\title{
Compositional and Morphological Engineering of Mixed Cation Perovskite Films for Highly Efficient Planar and Flexible Solar Cells with Reduced Hysteresis
}

Changlei Wang, ${ }^{a, b}$ Dewei Zhao, ${ }^{, b}$ Yue Yu, ${ }^{b}$ Niraj Shrestha, ${ }^{b}$ Corey R. Grice, ${ }^{b}$ Weiqiang Liao, ${ }^{\mathrm{b}}$ Alexander J. Cimaroli, ${ }^{\mathrm{b}}$ Jing Chen, ${ }^{\mathrm{c}}$ Randy J. Ellingson, ${ }^{\mathrm{b}}$ Xingzhong Zhao, ${ }^{*, a}$ Yanfa Yan*,b

${ }^{a}$ Key Laboratory of Artificial Micro/Nano Structures of Ministry of Education, School of Physics and Technology, Wuhan University, Wuhan, 430072, China

${ }^{b}$ Department of Physics and Astronomy, and Wright Center for Photovoltaics Innovation and Commercialization, The University of Toledo, Toledo, $\mathrm{OH} 43606$, USA.

${ }^{\mathrm{c}}$ School of Electronic Science and Engineering, Southeast University, Nanjing, 210096, China

*Corresponding author.

E-mail addresses: dewei_zhao@hotmail.com (D. Zhao); xzzhao@whu.edu.cn (X. Zhao); Yanfa.Yan@utoledo.edu (Y. Yan). 


\section{Abstract:}

We report on compositional and morphological engineering of mixed methylammonium (MA) and formamidinium (FA) lead triiodide $\left(\mathrm{MA}_{1-\mathrm{x}} \mathrm{FA}_{\mathrm{x}} \mathrm{PbI}_{3}\right)$ perovskite absorber layers to produce highly efficient planar and flexible perovskite solar cells (PVSCs) with reduced hysteresis. Incorporation of FA into the $\mathrm{MAPbI}_{3}$ extends the absorption edge of the perovskite to longer wavelengths, leading to enhanced photocurrent of the resultant PVSCs. Moreover, adding a small amount of lead thiocyanate $\left(\mathrm{Pb}(\mathrm{SCN})_{2}\right)$ additive into mixed perovskite precursor solutions significantly enlarges the grain size and prolongs the carrier lifetime, leading to improved device performance. With optimal compositional and morphological engineering, the average power conversion efficiency (PCE) improves from $15.74 \pm 0.74 \%$ for pure $\mathrm{MAPbI}_{3} \mathrm{PVSCs}$ to $19.40 \pm 0.32 \%$ for $\mathrm{MA}_{0.7} \mathrm{FA}_{0.3} \mathrm{PbI}_{3} \mathrm{PVSCs}$ with $3 \% \mathrm{~Pb}(\mathrm{SCN})_{2}$ additive, exhibiting a high reproducibility and small hysteretic behavior. The best PVSC achieves a PCE of 20.10 (19.85)\% measured under reverse (forward) voltage scan. Furthermore, the compositional and morphological engineering allowed the fabrication of efficient flexible PVSCs on indium-doped $\mathrm{SnO}_{2}$ (ITO)/polyethylene terephthalate (PET) substrates, with the best PCE of 17.96 (16.10)\% with a $V_{\mathrm{OC}}$ of $1.076(1.020) \mathrm{V}$, a $J_{\mathrm{SC}}$ of $22.23(22.23) \mathrm{mA} / \mathrm{cm}^{2}$ and a FF of 75.10 (71.02)\% when measured under reverse (forward) voltage scan. Our approach provides an effective pathway to fabricate highly efficient and reproducible planar PVSCs. 
Keywords: perovskite solar cells, compositional and morphological engineering, hysteresis, flexible solar cells 


\section{Introduction}

Organic-inorganic metal halide perovskite solar cells (PVSCs) have gained tremendous attention in the past few years, ${ }^{[1-14]}$ and the record power conversion efficiency (PCE) has recently exceeded 22\%. ${ }^{[5-7]}$ The bandgap (Eg) of the most commonly studied organic-inorganic perovskite absorber material, methylammonium lead triiodide $\left(\mathrm{MAPbI}_{3}\right)$ with $\mathrm{Eg} \sim 1.60 \mathrm{eV}$, is slightly higher than the optimal $\mathrm{Eg}$ range $(1.2-1.45 \mathrm{eV})$ for single junction solar cells per the Shockley - Queisser limit. ${ }^{[15,16]} \mathrm{A}$ relatively smaller Eg is desirable for boosting the performance by increasing the portion of photons absorbed, thereby increasing the photogenerated current. Formanidinium lead triiodide $\left(\mathrm{FAPbI}_{3}\right)$ perovskite exhibits an $\mathrm{Eg}$ of $\sim 1.45 \mathrm{eV}$, ${ }^{[17-20]}$ which is much more suitable for single junction solar cells. However, $\mathrm{FAPbI}_{3}$ perovskite films often contain a small portion of the undesirable yellow phase ( $\delta$-phase),${ }^{[7,21,22]}$ which adversely affects the cell performance. Combining different

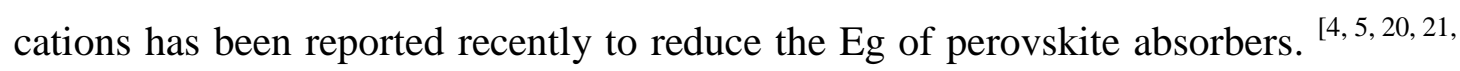
23-25] Among these methods, mixing MA and FA cations has shown promising results, ${ }^{[5,8,26]}$ but it is challenging to obtain good device reproducibility due to the facile formation of the undesirable $\delta$-phase of $\mathrm{FAPbI}_{3}{ }^{[7,21]}$ Mixing $\mathrm{MAPbI}_{3}$ with $\mathrm{FAPbI}_{3}$ precursors has been proven to be an effective way to fabricate mixed FA and MA planar PVSCs. ${ }^{[2]}$ However, a significant drawback of this approach is that the resultant $\left(\mathrm{MA}_{1-\mathrm{x}} \mathrm{FA}_{\mathrm{x}} \mathrm{PbI}_{3}\right)$ perovskite thin films contain rather small grains, hindering the use of relatively thick perovskite absorbers which is needed for maximum light absorption. On the other hand, the high annealing temperature of $150{ }^{\circ} \mathrm{C}$ for pure 
$\mathrm{FAPbI}_{3}$ hinders its application on flexible substrates, while mixing MA and FA will lower the formation temperature to $100{ }^{\circ} \mathrm{C}$ which is more compatible for flexible PVSCs.

High-quality perovskite film is a requisite for fabricating high-efficiency PVSCs. ${ }^{\text {[27-29] }}$ PVSCs with small grains and low crystallinity typically exhibit poor fill factors (FF's), because absorber layers exhibit high density of grain boundaries, which could cause charge recombination. ${ }^{[30,31]}$ Therefore, it is highly desirable to reduce the density of grain boundaries ${ }^{[26,31,32]}$ and/or passivate the grain boundaries with other materials, such as (6,6)-phenyl- $\mathrm{C}_{61}$-butyric acid methyl ester $(\mathrm{PCBM})$ and $\mathrm{PbI}_{2}{ }^{[33-35]}$ Various works have been reported to improve the performance of PVSCs, including perovskite film quality improvement and interfacial engineering of the devices. ${ }^{\text {[36-43] }}$ Recently, lead thiocyanate $\left(\mathrm{Pb}(\mathrm{SCN})_{2}\right)$ additives have been employed in $\mathrm{MAPbI}_{3}$ and $\mathrm{FA}_{1-\mathrm{x}} \mathrm{Cs}_{\mathrm{x}} \mathrm{PbI}_{3}$ perovskite films to enlarge the grains and increase the perovskite crystallinity. ${ }^{[24,44]}$ It was found that $\mathrm{Pb}(\mathrm{SCN})_{2}$ additives can significantly increase the grain size of perovskite films from about $200 \mathrm{~nm}$ to up to several micrometers, and the grain boundaries are passivated with excessive $\mathrm{PbI}_{2}{ }^{[24,44]}$

Here, we demonstrate that $\mathrm{Pb}(\mathrm{SCN})_{2}$ additives can also significantly enlarge the grain size of mixed MA and FA lead triiodide $\left(\mathrm{MA}_{1-\mathrm{x}} \mathrm{FA}_{\mathrm{x}} \mathrm{PbI}_{3}\right)$ perovskite thin films and lead to highly efficient planar PVSCs. Mixtures of MA and FA cations extend the absorption edge to longer wavelengths as compared to pure $\mathrm{MAPbI}_{3}$, leading to enhanced short-circuit current densities ( $J_{\mathrm{SC}}$ 's). Adding a small amount of $\mathrm{Pb}(\mathrm{SCN})_{2}$ additive into perovskite precursor remarkably increases the grain size of perovskite 
thin film and thus prolongs the carrier lifetime, which is responsible for the significantly enhanced device performance. With optimal compositional and morphological engineering, the averaged PCE of our PVSCs increases from $15.74 \pm 0.74 \%$ for pure $\mathrm{MAPbI}_{3}$ PVSCs $\left(0 \mathrm{wt} \% \mathrm{~Pb}(\mathrm{SCN})_{2}\right)$ cells to $19.40 \pm 0.32 \%$ for $\mathrm{MA}_{0.7} \mathrm{FA}_{0.3} \mathrm{PbI}_{3}$ PVSCs with $3 \mathrm{wt} \% \mathrm{~Pb}(\mathrm{SCN})_{2}$ additive. The best performing PVSC shows a PCE of $20.10(19.85) \%$ with an open-circuit voltage $\left(V_{\mathrm{OC}}\right)$ of $1.121(1.119) \mathrm{V}$, a $J_{\mathrm{SC}}$ of $22.85(22.86) \mathrm{mA} / \mathrm{cm}^{2}$ and a $\mathrm{FF}$ of $78.46(77.60) \%$ when measured under reverse (forward) voltage scan, respectively. Furthermore, the compotional and morphological engineering allowed the fabrication of efficient flexible PVSCs on indium-doped $\mathrm{SnO}_{2}$ (ITO)/polyethylene terephthalate (PET) substrates, with the best PCE of $17.96(16.10) \%$ with a $V_{\mathrm{OC}}$ of $1.076(1.020) \mathrm{V}$, a $J_{\mathrm{SC}}$ of $22.23(22.23) \mathrm{mA} / \mathrm{cm}^{2}$ and a FF of 75.10 (71.02)\% when measured under reverse (forward) voltage scan. Our results demonstrate that $\mathrm{Pb}(\mathrm{SCN})_{2}$ additives can be used to effectively increase the crystal quality of the mixed cation perovskite absorbers and improve the photovoltaic performance of planar PVSCs with the regular cell configuration.

\section{Experimental Section}

\section{Preparation of ESLs}

FTO glass (Pilkington, NSG TEC-15) was cleaned with detergent, facilitated by ultrasonication in water, acetone and iso-propanol baths successively before deposition of $\mathrm{SnO}_{2}$ ESLs. The $\mathrm{SnO}_{2}$ layer was deposited on the FTO substrates as reported previously. ${ }^{[45]}$ Plasma-enhanced atomic layer deposition (PEALD) process 
was done with an equipment of Ensure Scientific Group AutoALD-PE V2.0 equipped with a plasma generator. Tetrakis(dimethylamino)-tin(IV) (99\%, TDMA-Sn, Strem Chemicals Inc.) was used as the Sn precursor. Oxygen and Argon are used as oxidizer and carrier gases, respectively. The temperature of the reaction is fixed at $100{ }^{\circ} \mathrm{C}$ during the deposition process.

\section{Perovskite precursor preparation}

Lead iodide $\left(\mathrm{PbI}_{2}\right.$, Alfa Aesar, 99.9985\%), methylammonium iodide (MAI, Dyesol), formamidinium iodide (FAI, Dyesol), lead thiocyanate $\left(\mathrm{Pb}(\mathrm{SCN})_{2}\right.$, Sigma-Aldrich, 99.5\%), dimethyl sulfoxide (DMSO, Sigma-Aldrich, 99.8\%) and N,N-dimethylformamide (DMF, Sigma-Aldrich, 99.8\%) are purchased and used without further purification. The perovskite precursor was prepared using a Lewis acid-base adduct approach with the mixture of MAI, FAI, $\mathrm{PbI}_{2}$, and DMSO in DMF, where the molar ratio of DMSO and $\mathrm{PbI}_{2}$ is $1: 1 .^{[46,47]} \mathrm{A} 45 \%$ by weight precursor solution of $\mathrm{MAPbI}_{3}$ was prepared with $\mathrm{PbI}_{2}, \mathrm{MAI}$ and DMSO (molar ratio=1:1:1) in DMF. The solution was stirred for 12 hours on a $60{ }^{\circ} \mathrm{C}$ hot plate before deposition. The $\mathrm{FAPbI}_{3}$ precursor solution was made in the same process. The $\mathrm{MA}_{1-\mathrm{x}} \mathrm{FA}_{\mathrm{x}} \mathrm{PbI}_{3}$ precursor was prepared by mixing two different solutions together with different volume ratio, where the ratio of MAI and FAI is changed from 1:0 to $0: 1(x=0,0.2$, $0.3,0.4,0.6,0.8,1.0)$. The resulting mixed precursor solution was stirred for one hour on a $60{ }^{\circ} \mathrm{C}$ hotplate and then purified using a $0.45 \mu \mathrm{m}$ filter before spin-coating.

The precursors with $\mathrm{Pb}(\mathrm{SCN})_{2}$ additives are prepared with fixed amounts of $\mathrm{Pb}(\mathrm{SCN})_{2}$ with respect to the weight of $\mathrm{PbI}_{2}$, where the content of $\mathrm{Pb}(\mathrm{SCN})_{2}$ ranging 
from $0 \%$ to $5 \%$.

\section{Fabrication of PVSCs}

$\mathrm{C}_{60}$-SAM was deposited on PEALD $\mathrm{SnO}_{2}$ as previously reported. ${ }^{[45]}$ The perovskite precursor solution was spin-coated on the ESL first at $500 \mathrm{rpm}$ for $3 \mathrm{~s}$, and then at $4000 \mathrm{rpm}$ for $60 \mathrm{~s}$ using a fast deposition-crystallization technique with diethyl ether as the anti-solvent agent. After spin coating, the perovskite film was annealed at $65{ }^{\circ} \mathrm{C}$ for 2 minutes and then $100{ }^{\circ} \mathrm{C}$ for 5 minutes. All of these processes were carried out in a $\mathrm{N}_{2}$ filled glove box.

\section{2,2',7,7'-tetrakis(N,N'-di-p-methoxyphenylamine)-9,9'-spirobifluorene}

(Spiro-OMeTAD) was used as the HSL and deposited on the perovskite film at 2000 rpm for 60 seconds. The Spiro-OMeTAD was co-doped using Co-TFSI and Li-TFSI. The Spiro-OMeTAD solution was prepared by dissolving $72.3 \mathrm{mg}$ Spiro-OMeTAD (Shenzhen Feiming Science and Technology Co., Ltd., 99.0\%) in $1 \mathrm{~mL}$ chlorobenzene (CB) with $28 \mathrm{uL}$ 4-tert-butylpyridine (TBP) (Sigma-Aldrich, 96\%), $18 \mathrm{uL}$ Li-bis-(trifluoromethanesulfonyl) imide (Li-TFSI) (Sigma-Aldrich, 99.95\%) (520 $\mathrm{mg} / \mathrm{mL}$ in acetonitrile) and $18 \mathrm{uL} \mathrm{Co}(\mathrm{II})-\mathrm{TFSI}$ salt (FK102, Dyesol) $(300 \mathrm{mg} / \mathrm{mL}$ in acetonitrile). A layer of $80 \mathrm{~nm}$ gold $(\mathrm{Au})$ was then deposited on the top of Spiro-OMeTAD using thermal evaporation. The working area of the devices was 0.08 $\mathrm{cm}^{2}$ as defined by a shadow mask during the Au evaporation.

\section{Characterizations}

$J-V$ curves were measured using a Keithley2400 sourcemeter under standard AM 1.5G illumination using solar simulator (PV Measurements Inc.) with an output 
intensity of $100 \mathrm{~mW} / \mathrm{cm}^{2}$. For light intensity dependence test, the light intensity was later adjusted between 1 and $100 \mathrm{~mW} / \mathrm{cm}^{2}$ using neutral density filters. EQE measurement was carried out with an EQE system (PV Measurements Inc,) using 100 $\mathrm{Hz}$ chopped monochromatic light ranging from $300 \mathrm{~nm}$ to $900 \mathrm{~nm}$ under otherwise near-dark test conditions. The top-view and cross section structures of perovskite films and PVSCs were characterized with a field emission SEM instrument (Hitachi S-4800). Crystallinity and the crystal structure of the perovskite layer were analyzed with an Ultima III X-ray Diffractometer using a Ni-filtered $\mathrm{Cu} \mathrm{K}_{\alpha}$ X-ray source (Rigaku Corp.). Absorbance spectra were obtained with a UV-vis spectrophotometer (PerkinElmer Lambda 1050). Sheet resistance was measured using four-point probe method resistivity test system (PRO4-440N, Lucas labs). For steady-state photoluminescence (PL) and time resolved photoluminescence (TRPL) measurements, perovskite films were fabricated by spin-coating perovskite precursors on glass substrates followed by coating another encapsulating layer of polymethylmethacrylate (PMMA) after thermal annealing. PL measurements were performed in ambient air at room temperature. Samples were illuminated through the film side. A $532 \mathrm{~nm}$ continuous-wave laser (beam diameter $\approx 90 \mu \mathrm{m}$ ) at $40 \mathrm{~mW} / \mathrm{cm}^{2}$ was used as an excitation wavelength for steady-state PL measurement. PL signal was detected via Symphony-II CCD (from Horiba) detector after a $300 \mathrm{~g} \mathrm{~mm}^{-1}$ grating monochromator (Integration time $=0.5 \mathrm{~s}$ ). For TRPL measurements, samples were excited by a 532 $\mathrm{nm}$ pulsed laser (pulse width $=5 \mathrm{ps}$, beam diameter $\approx 150 \mu \mathrm{m}$ ) at $10^{10}$ photons pulse $^{-1}$ $\mathrm{cm}^{-2}$. TRPL measurements were performed with time correlated single photon 
counting (TCSPC) module (Becker \& Hickel Simple Tau SPCM 130-E/M module) and the radiative recombination events were detected (Integration time $=600 \mathrm{~s}$ ) via hybrid APD/PMT module (R10467U-50). PL decays of perovskite films with $\mathrm{x}=0.3$, 0.4, 0.6 and 0.8 are single exponential while bi-exponential PL decays are observed in case of $x=0,0.2$ and 1.0. In case of bi-exponential PL decay, the photoluminescence intensity contribution of each component is proportional to the product of amplitude $\left(\mathrm{A}_{\mathrm{i}}\right)$ and life time $\left(\tau_{\mathrm{i}}\right)$. Therefore, the intensity average lifetime of bi-exponential PL decay is calculated as

Mean life time $=(\tau)=\frac{A_{1} \tau_{1}^{2}+A_{2} \tau_{2}^{2}}{A_{1} \tau_{1}+A_{2} \tau_{2}}$

\section{Results and discussion}

(a)

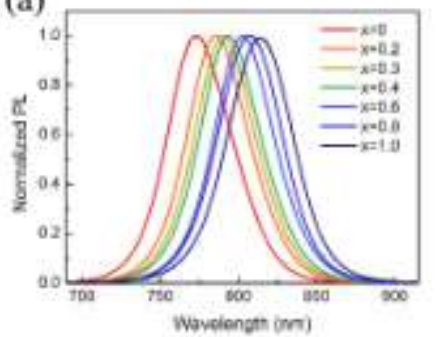

(d)

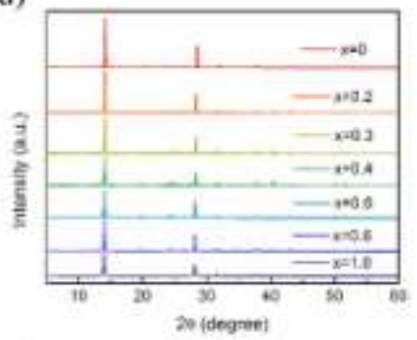

(g)

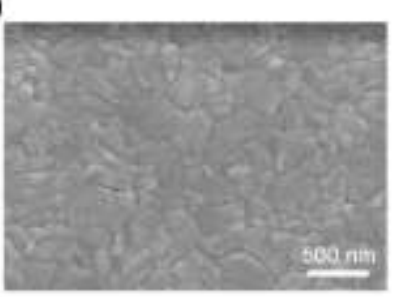

(b)

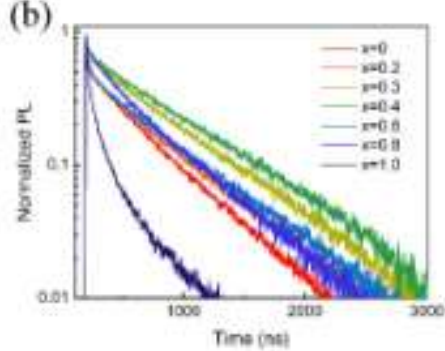

(e)

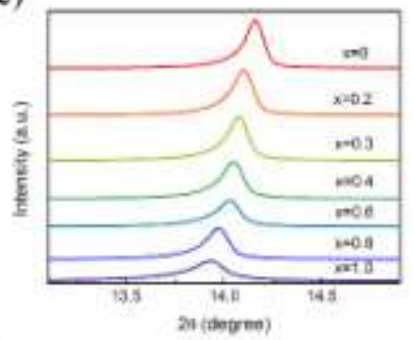

(h)

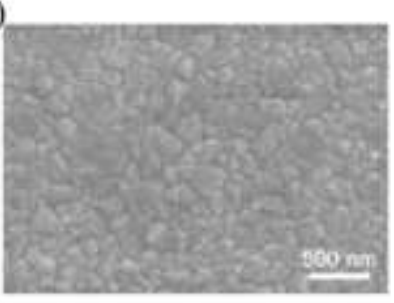

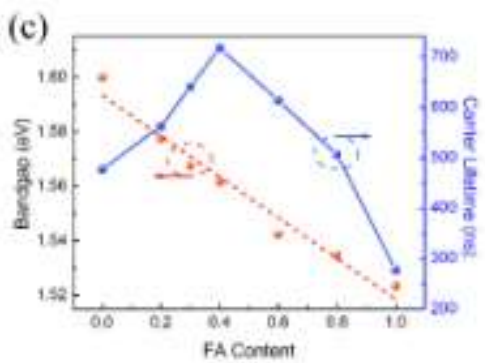

(f)
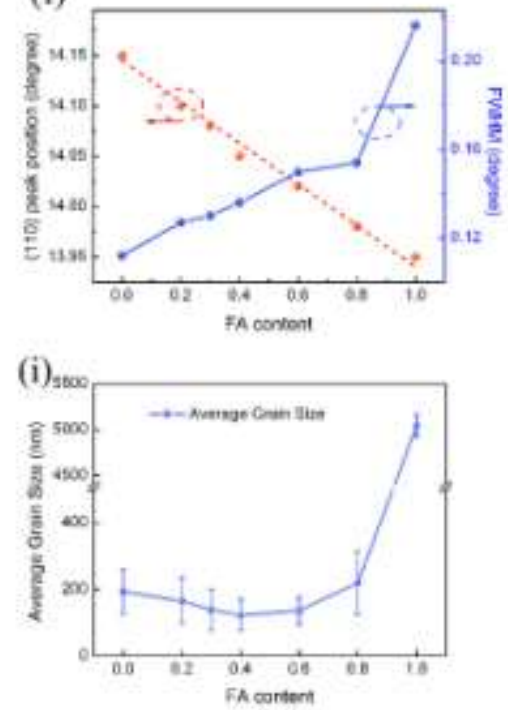
Fig. 1. Characterizations of $\mathrm{MA}_{1-\mathrm{x}} \mathrm{FA}_{\mathrm{x}} \mathrm{PbI}_{3}$ films with $\mathrm{x}$ varying from 0 to 1 . (a) Steady-state PL spectra and (b) PL decays of $\mathrm{MA}_{1-\mathrm{x}} \mathrm{FA}_{\mathrm{x}} \mathrm{PbI}_{3}$ films. (c) Bandgap calculated from the PL emission peaks and average photogenerated carrier lifetimes. (d) XRD patterns and (e) magnified XRD patterns of the (110) diffraction peak. (f) (110) diffraction peak position from XRD and FWHM of (110) peak of $\mathrm{MA}_{1-\mathrm{x}} \mathrm{FA}_{\mathrm{x}} \mathrm{PbI}_{3}$ films. Top-view SEM images of (g) $\mathrm{MAPbI}_{3}$ and (h) $\mathrm{MA}_{0.7} \mathrm{FA}_{0.3} \mathrm{PbI}_{3}$ films. (i) Average grain size obtained from SEM images with different FA content.

The $\mathrm{MA}_{1-\mathrm{x}} \mathrm{FA}_{\mathrm{x}} \mathrm{PbI}_{3}$ perovskite precursors were prepared by adding a $\mathrm{FAPbI}_{3}$ precursor solution into a $\mathrm{MAPbI}_{3}$ precursor with different molar ratios. The composition of a perovskite film is defined by the stoichiometry of mixed precursors. ${ }^{[5]}$ The anneal temperatures of the $\mathrm{MA}_{1-\mathrm{x}} \mathrm{FA}_{\mathrm{x}} \mathrm{PbI}_{3}$ perovskite films are 100 ${ }^{\circ} \mathrm{C}$ for $\mathrm{x}<0.4,130{ }^{\circ} \mathrm{C}$ for $\mathrm{x}=0.6$ and $0.8,150{ }^{\circ} \mathrm{C}$ for pure $\mathrm{FAPbI}_{3}$. A slightly higher annealing temperature is used for the film with a higher FA content, because $\mathrm{FAPbI}_{3}$ has a yellow-to-black ( $\delta$ to $\alpha$ ) phase transition when heated to temperatures of around $150{ }^{\circ} \mathrm{C} .{ }^{[17,18,48]}$ The steady-state photoluminescence (PL) spectra of the perovskite film with different compositions are shown in Fig. 1(a). As the FA content increases, the emission peak shows a red shift from 775 to $814 \mathrm{~nm}$, which confirms the alloying of $\mathrm{FAPbI}_{3}$ and $\mathrm{MAPbI}_{3}$. The Eg calculated from the PL emission peak position decreases linearly with the concentration increase of FA in $\mathrm{MAPbI}_{3}$ (Fig. 1(c)), consistent with previous work reported in literature. ${ }^{[23]}$ In addition, as shown in Fig. $\mathrm{S} 1$, the absorption onset of perovskite films shifts from $775 \mathrm{~nm}$ to $814 \mathrm{~nm}$ as observed from UV-vis spectroscopic measurements, in good agreement with the Eg trend obtained from the PL results. It is worth noting that the mixed MA and FA perovskite films show higher absorption compared to pure $\mathrm{MAPbI}_{3}$, which is beneficial for the enhancement of photogenerated currents. 
In order to evaluate the effect of MA and FA alloy on the charge carrier lifetime, time resolved photoluminescence (TRPL) measurements were conducted to extract the photogenerated carrier lifetimes. Fig. 1(b) shows the normalized PL decays of perovskite films with various FA contents. PL decays of perovskite films with $\mathrm{x}=0.3$, 0.4, 0.6 and 0.8 are single exponential indicating the absence of surface or interface recombination while bi-exponential PL decays are observed in case of $\mathrm{x}=0,0.2$ and 1.0. The mean lifetime first increases and reaches a maximum value of $708 \mathrm{~ns}$ at $\mathrm{x}=0.4$, suggesting a prolonged carrier lifetime with the incorporation of FA. However, further increase in the FA content $60 \%(x>0.6)$ leads to the decrease in carrier lifetime, indicating the increased charge recombination, possibly due to the decreased film crystallinity (see discussions below). The TRPL results are summarized in Table S1.

X-ray diffraction (XRD) was carried out to evaluate the crystallinity of the mixed MA and FA perovskite films, as shown in Fig. 1(d). The (110) peak position shifts to lower angles with higher FA content, shown in Fig. 1(e), corresponding to the increased lattice constants after FA incorporation. This confirms the successful incorporation of FA cation into the perovskite crystal lattice, since the FA cation has a relatively larger ionic radius $(1.9-2.2 \AA)$ than MA $(1.8 \AA) .{ }^{[5]}$ The full width half maximum (FWHM) of the (110) diffraction peak increases monotonically with increasing FA content. Typically, decreased grain size and/or increased density of defects (lower crystallinity) are responsible for the increase of FWHM. Because the average grain size increase as the FA content increases, the increased FWHM indicates decreased film crystallinity, which is likely attributable to the fact that the 
pure $\alpha$-phase of $\mathrm{FAPbI}_{3}$ is thermally unstable and it can easily revert to the non-perovskite $\delta$-phase at ambient temperature, thus disrupting the single-phase crystallinity. ${ }^{[5,26]}$ Therefore, pure $\mathrm{FAPbI}_{3}$ perovskite is not ideal for fabricating highly efficient PVSCs due to the lower crystallinity despite having a more suitable Eg value. It is known that alloying $\mathrm{FAPbI}_{3}$ with relatively stable perovskite materials, such as $\mathrm{MAPbBr}_{3}{ }^{[5,8,49]}$ and $\mathrm{CsPbI}_{3}{ }^{[8,50]}$ can stabilize the desirable $\alpha$-phase of $\mathrm{FAPbI}_{3}$, which may reinforce the observation that the films with increasing MA content $(x>0.2)$ appear to have improved crystallinity than the more FA-rich films. Although the $\mathrm{MA}_{1-\mathrm{x}} \mathrm{FA}_{\mathrm{x}} \mathrm{PbI}_{3}$ perovskite films exhibit improved light absorption compared to $\mathrm{MAPbI}_{3}$ perovskite films, their grain sizes are smaller, as shown in Fig. 1(g), (h) and Fig. S2. The averaged grain size of the perovskite films with FA content less than 0.8 appears to be similar, around $100-200 \mathrm{~nm}$. This is possibly due to the formation of Lewis acid-base adduct of $\mathrm{FAI} \cdot \mathrm{PbI}_{2} \cdot \mathrm{DMSO}$, which is relatively weaker than MAI. $\mathrm{PbI}_{2} \cdot \mathrm{DMSO}^{[46,47]}$ Therefore, the grain size is relatively small in the mixed MA and FA perovskite films. Small grains would lead to thin films with high density of grain boundaries, which could exhibit high charge recombination. ${ }^{[31]}$ For pure $\mathrm{FAPbI}_{3}$, although the grain size is large, the film is very rough, likely due to the higher nucleus formation energy of $\mathrm{FAPbI}_{3}$, leading to grains with large size but lower crystallinity. ${ }^{[26]}$ Therefore, it is highly desirable to increase the grain size and alleviate the charge recombination in the $\mathrm{MA}_{1-\mathrm{x}} \mathrm{FA}_{\mathrm{x}} \mathrm{PbI}_{3}$ perovskite films in order to further improve the PCEs of PVSCs. 


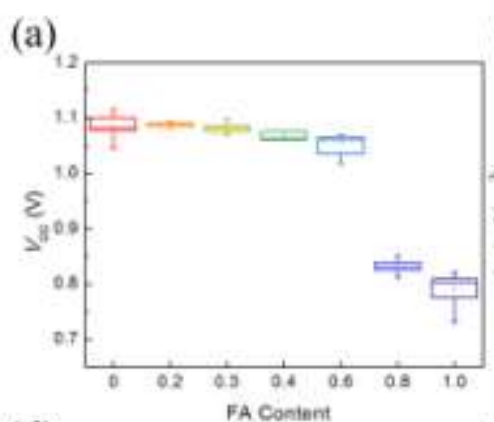

(b)

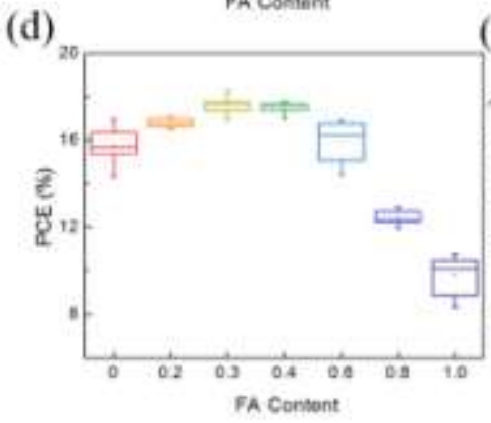

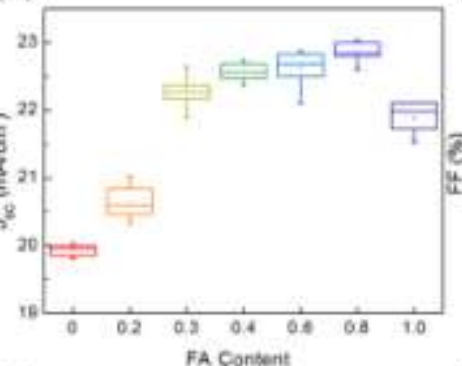

(e)

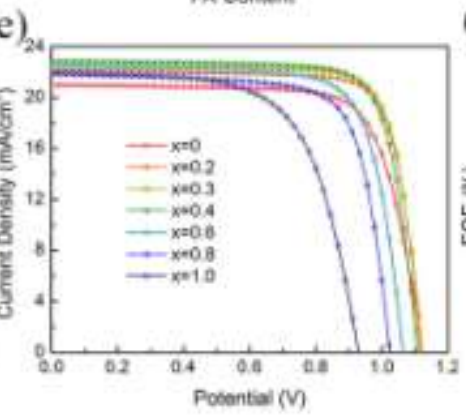

(c)

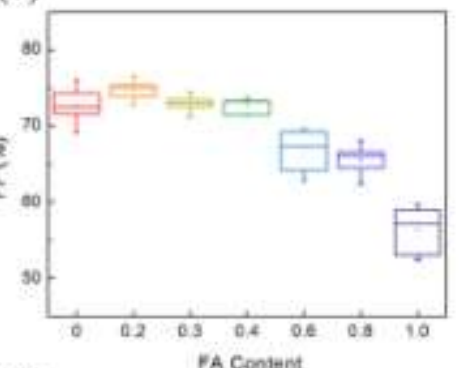

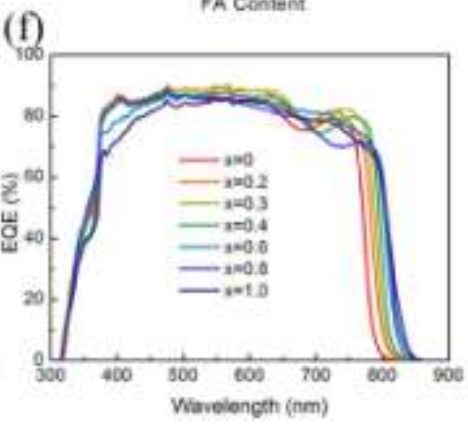

Fig. 2. Photovoltaic performance of PVSCs based on $\mathrm{MA}_{1-\mathrm{x}} \mathrm{FA}_{\mathrm{x}} \mathrm{PbI}_{3}$ absorber with $\mathrm{x}$ varying from 0 to 1 , showing the statistics of (a) $V_{\mathrm{OC}}$, (b) $J_{\mathrm{SC}}$, (c) FF and (d) PCE. (e) $J-V$ curves and (f) EQE spectra of best-performing $\mathrm{MA}_{1-\mathrm{x}} \mathrm{FA}_{\mathrm{x}} \mathrm{PbI}_{3}$ PVSCs.

We fabricated PVSCs using $\mathrm{MA}_{1-\mathrm{x}} \mathrm{FA}_{\mathrm{x}} \mathrm{PbI}_{3}$ absorbers with a planar regular device structure of fluorine doped $\mathrm{SnO}_{2} \quad(\mathrm{FTO}) / \mathrm{SnO}_{2} / \mathrm{C}_{60}-\mathrm{SAM} \mathrm{MA}_{1-\mathrm{x}} \mathrm{FA}_{\mathrm{x}} \mathrm{PbI}_{3}$ perovskite/spiro-OMeTAD/Au, ${ }^{[51-53]}$ where

$\mathrm{C}_{60}-\mathrm{SAM}$ is $\mathrm{C}_{60}$-self-assembled-monolayer and Spiro-OMeTAD is 2,2',7,7'-tetrakis(N,N'-di-p-methoxyphenylamine)-9,9'- $\quad$ spirobifluorene. The photovoltaic performances of the $\mathrm{MA}_{1-\mathrm{x}} \mathrm{FA}_{\mathrm{x}} \mathrm{PbI}_{3}$ PVSCs are summarized in Fig. 2 and Table S2. The $V_{\mathrm{OC}}$ of the PVSCs decreases, but the $J_{\mathrm{SC}}$ of the PVSCs increases as the FA content increases due to the decreased Eg, except for the case for $x=1$. From the photographs of these perovskite films (Fig. S3), it is seen that the pure $\mathrm{FAPbI}_{3}$ film is obstructed from the backside (glass side), and therefore the illuminated light is blocked, resulting in the reduction in the light harvesting and the low photocurrent. 
The FF slightly increases when $\mathrm{x}$ increase from 0 to 0.4 , likely due to the prolonged carrier lifetime. However, when $\mathrm{x}$ is larger than 0.6, the FF deteriorates to below $70 \%$. This may be due to the poor crystallinity and short carrier lifetimes of these perovskite films. As a result, the optimal device performance is obtained at $\mathrm{x}=0.3$ $\left(\mathrm{MA}_{0.7} \mathrm{FA}_{0.3} \mathrm{PbI}_{3}\right)$ due to both increased absorption and prolonged charge carrier lifetime, generating an average PCE of $17.61 \pm 0.32 \%$. However, when the FA content is above $60 \%(x>0.6)$, the device performance decreases dramatically due to the significant drop in $V_{\mathrm{OC}}$ and $\mathrm{FF}$, likely due to the poor film morphology and low crystallinity as discussed above. The representative $J$ - $V$ curves of the best-performing device for composition and the corresponding external quantum efficiencies (EQEs) are shown in Fig. 2 (e) and (f).

Various approaches have been proposed to increase the grain size of perovskite thin films in order to improve the device performance. ${ }^{[30,31]}$ Previously, we have used $\mathrm{Pb}(\mathrm{SCN})_{2}$ additives to enlarge the grain sizes of $\mathrm{MAPbI}_{3}$ and $\mathrm{FA}_{1-\mathrm{x}} \mathrm{Cs}_{\mathrm{x}} \mathrm{PbI}_{3}$ perovskites films to obtain improved device performances. ${ }^{[24,44]}$ Herein, we find that the $\mathrm{Pb}(\mathrm{SCN})_{2}$ additives in combined $\mathrm{MAPbI}_{3}$ and $\mathrm{FAPbI}_{3}$ precursor solutions can also effectively enlarge the grain size of $\mathrm{MA}_{0.7} \mathrm{FA}_{0.3} \mathrm{PbI}_{3}$ perovskite thin films. We incorporate various amounts of $\mathrm{Pb}(\mathrm{SCN})_{2}$ additives ranging from 0 to $5 \mathrm{wt} \%$ with respect to $\mathrm{PbI}_{2}$ into the mixed precursors to investigate the effect of $\mathrm{Pb}(\mathrm{SCN})_{2}$ additives on the film morphology, crystalline, and device performance. We focused on the composition of $\mathrm{MA}_{0.7} \mathrm{FA}_{0.3} \mathrm{PbI}_{3}$ based on the above results. 

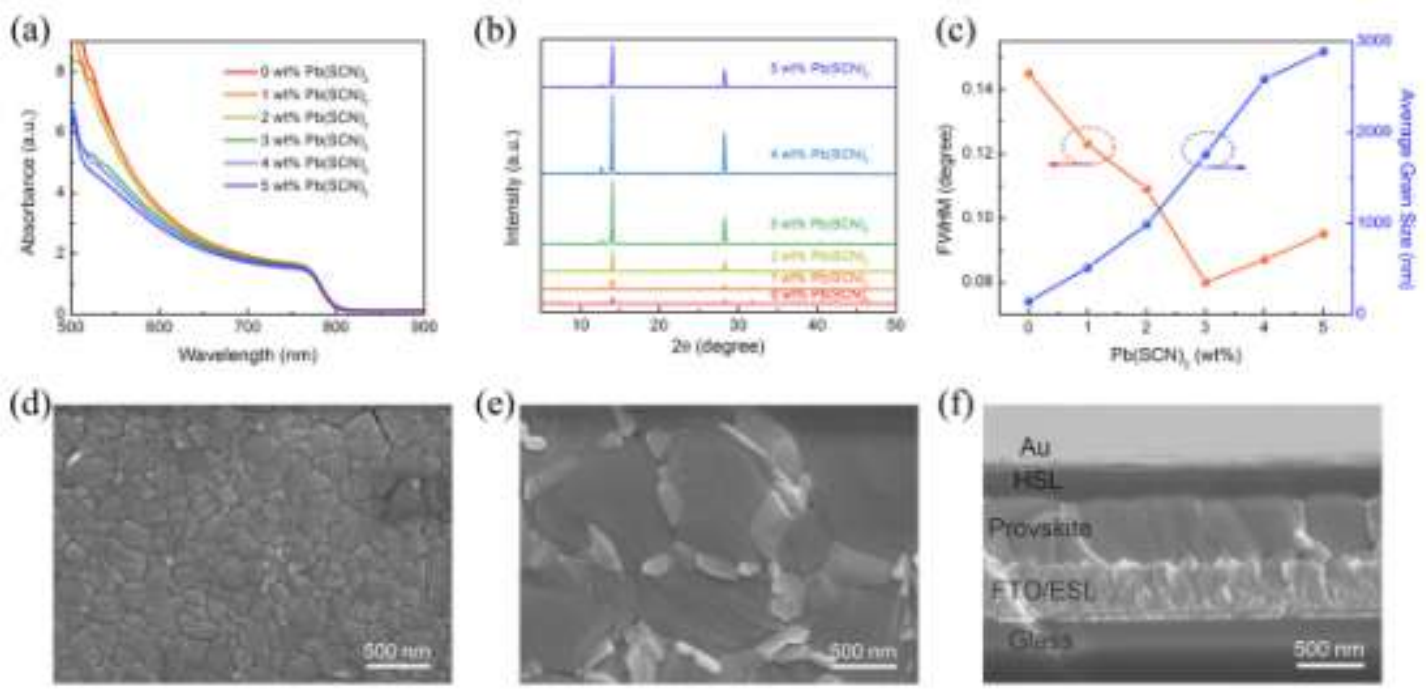

Fig. 3. Characterizations of $\mathrm{MA}_{0.7} \mathrm{FA}_{0.3} \mathrm{PbI}_{3}$ films with various content of $\mathrm{Pb}(\mathrm{SCN})_{2}$ additive. (a) UV-vis spectra, (b) XRD patterns, (c) FWHM of (110) diffraction peak and average grain size of $\mathrm{MA}_{0.7} \mathrm{FA}_{0.3} \mathrm{PbI}_{3}$ films with various content of $\mathrm{Pb}(\mathrm{SCN})_{2}$ additive. Plane-view SEM images of (d) $\mathrm{MA}_{0.7} \mathrm{FA}_{0.3} \mathrm{PbI}_{3}$ and (e) $\mathrm{MA}_{0.7} \mathrm{FA}_{0.3} \mathrm{PbI}_{3}+3$ wt $\%$ $\mathrm{Pb}(\mathrm{SCN})_{2}$ films. (f) Cross-section SEM image of the planar structure PVSC.

Fig. 3a shows the absorbance spectra of $\mathrm{MA}_{0.7} \mathrm{FA}_{0.3} \mathrm{PbI}_{3}$ perovskite films with various $\mathrm{Pb}(\mathrm{SCN})_{2}$ contents in the precursors, exhibiting identical absorption edges at around $810 \mathrm{~nm}$. This indicates that the incorporation of $\mathrm{Pb}(\mathrm{SCN})_{2}$ additive in the precursors does not change the Eg's of the perovskite absorbers, similar to our previous studies. ${ }^{[24,}{ }^{44]} \mathrm{Pb}(\mathrm{SCN})_{2}$ additive in the precursors also leads to $\mathrm{MA}_{0.7} \mathrm{FA}_{0.3} \mathrm{PbI}_{3}$ perovskite films with excessive $\mathrm{PbI}_{2}$ locating at the grain boundaries, as verified by XRD and SEM. As shown in Fig. 3b, the intensity of (110) diffraction peak at $14.2^{\circ}$ increased dramatically compared to the $\mathrm{MA}_{0.7} \mathrm{FA}_{0.3} \mathrm{PbI}_{3}$ perovskite film without $\mathrm{Pb}(\mathrm{SCN})_{2}$, indicating higher crystallinity of the resulted films. Stronger $\mathrm{PbI}_{2}$ peaks at $12.8^{\circ}$ are observed for $\mathrm{MA}_{0.7} \mathrm{FA}_{0.3} \mathrm{PbI}_{3}$ perovskite films with higher $\mathrm{Pb}(\mathrm{SCN})_{2}$ concentrations, indicating increased $\mathrm{PbI}_{2}$ in these perovskite films. The FWHM values of the (110) diffraction peak of perovskite films with various $\mathrm{Pb}(\mathrm{SCN})_{2}$ concentration 
are plotted in Fig. 3(c). It is seen that the FWHM becomes smaller first and reaches a minimum value at $3 \mathrm{wt} \%$, and then increases. It can be inferred that the addition of $\mathrm{Pb}(\mathrm{SCN})_{2}$ will increase the crystallinity, which is due to the formation of large grain size with the addition of $\mathrm{Pb}(\mathrm{SCN})_{2}$ as discussed in our previous works. ${ }^{[24,44]}$ However, if the amount of $\mathrm{Pb}(\mathrm{SCN})_{2}$ is too high, a large amount of $\mathrm{PbI}_{2}$ will be present in the resultant perovskite films, which reduces the film phase purity and is detrimental for the device efficiency. By comparing the SEM images of perovskite films without $(0$ wt $\%$ ) and with $3 \mathrm{wt} \% \mathrm{~Pb}(\mathrm{SCN})_{2}$, it is seen that the average grain size is increased to $1760 \mathrm{~nm}$ for $3 \mathrm{wt} \% \mathrm{~Pb}(\mathrm{SCN})_{2}$ perovskite from $142 \mathrm{~nm}$ for $0 \mathrm{wt} \% \mathrm{~Pb}(\mathrm{SCN})_{2}$ perovskite, implying an increase of grain size by a factor of 12 . The grains are much larger than the film thickness (about $500 \mathrm{~nm}$ ) of our typical perovskites layers as shown in the cross-sectional SEM image (Fig. 3(f)), leading to less horizontally oriented grain boundaries that may block charge transportation. ${ }^{[31]}$ A thin film with larger grains is expected to exhibit a lower carrier recombination rate than a thin film with smaller grains, resulting in an improved photovoltaic performance. The top-view SEM images of perovskite films with other different concentrations of $\mathrm{Pb}(\mathrm{SCN})_{2}$ are shown in Fig. S4. The average grain sizes are shown in Fig. 3(c), with the grain sizes increasing as the $\mathrm{Pb}(\mathrm{SCN})_{2}$ concentration increases. The grain size exceeds $2 \mu \mathrm{m}$ at $5 \mathrm{wt} \% \mathrm{~Pb}(\mathrm{SCN})_{2}$ additive. However, the performance of PVSCs with $5 \mathrm{wt} \% \mathrm{~Pb}(\mathrm{SCN})_{2}$ additive drops largely due to presence of a large amount of excessive $\mathrm{PbI}_{2}$. Images of $\mathrm{MA}_{0.7} \mathrm{FA}_{0.3} \mathrm{PbI}_{3}$ films with various concentration of $\mathrm{Pb}(\mathrm{SCN})_{2}$ additive are shown in Fig. S5. 


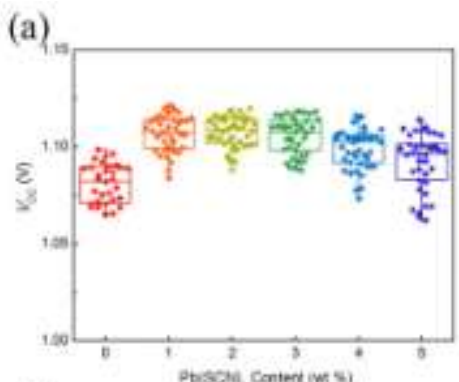

(d)

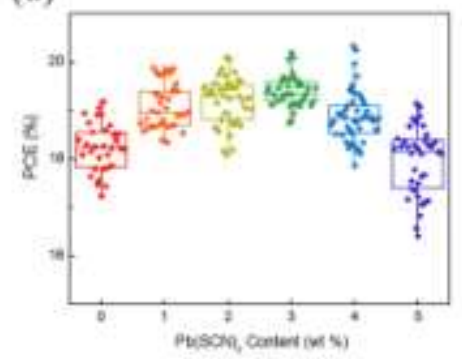

(b)

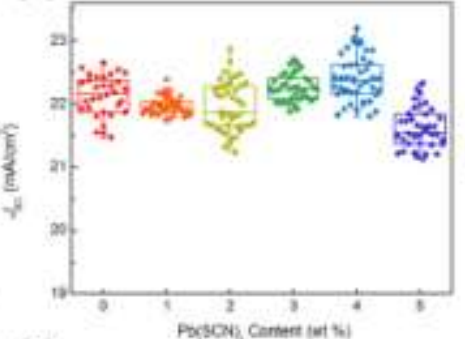

(e)

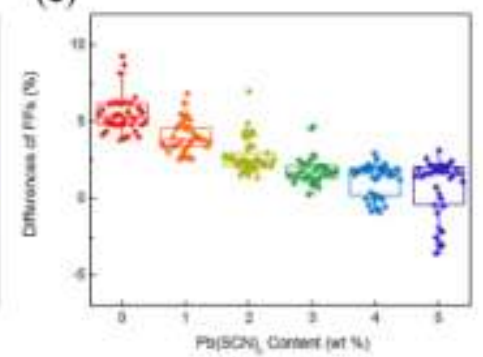

(c)

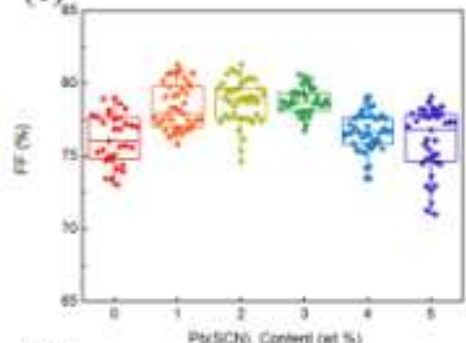

(f)

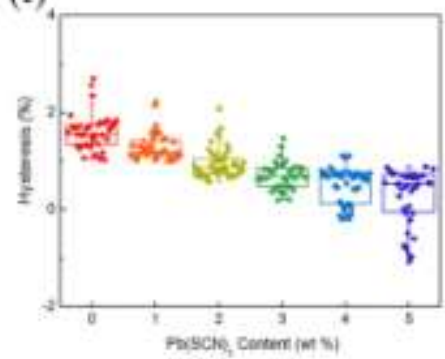

Fig. 4. Photovoltaic performance of $\mathrm{MA}_{0.7} \mathrm{FA}_{0.3} \mathrm{PbI}_{3}$ PVSCs with various concentrations of $\mathrm{Pb}(\mathrm{SCN})_{2}$ additives in the precursor. (a) $V_{\mathrm{OC}}$, (b) $J_{\mathrm{SC}}$, (c) FF, and (d) PCE measured under reverse voltage scans. The differences of (e) FFs and (f) PCEs (hysteresis) measured under reverse and forward scans.

Several batches of PVSCs with different concentrations of $\mathrm{Pb}(\mathrm{SCN})_{2}$ were fabricated. The statistical representations of the resulting photovoltaic parameters, calculated from 234 devices, are shown in Fig. 4 (a)-(d) and are also summarized in Table S3. The average $V_{\mathrm{OC}}$ first increases as the $\mathrm{Pb}(\mathrm{SCN})_{2}$ content increases and reaches a maximum value of $1.108 \pm 0.008 \mathrm{~V}$ at $2 \mathrm{wt} \% \mathrm{~Pb}(\mathrm{SCN})_{2}$. The $V_{\mathrm{OC}}$ starts to decrease when $\mathrm{Pb}(\mathrm{SCN})_{2}$ content further increases, due to the larger amount of $\mathrm{PbI}_{2}$ at the surface of the perovskite film, which will form a barrier between the perovskite and Spiro-OMeTAD layers. $\mathrm{PbI}_{2}$ has a larger bandgap $(\sim 2.3 \mathrm{eV})^{[34]}$ than perovskites, leading to relatively low conductivity and suppressing effective transfer of holes from the valence band of perovskite to the Spiro-OMeTAD. However, the $J_{\mathrm{SC}}$ does not change significantly and is maintained at around 21 to $23 \mathrm{~mA} / \mathrm{cm}^{2}$ regardless of the 
amount of $\mathrm{Pb}(\mathrm{SCN})_{2}$. This is because the excess $\mathrm{PbI}_{2}$ crystallites are mostly located at perovskite grain boundaries and on film surfaces, rather than the light incident side, hence has no effect on light illumination. The FF increases from $76.25 \%$ to over $78 \%$ by increasing the $\mathrm{Pb}(\mathrm{SCN})_{2}$ concentration, achieving a maximum value of $78.81 \pm 0.91 \%$ at $3 \mathrm{wt} \%$, and then decreases slightly when the $\mathrm{Pb}(\mathrm{SCN})_{2}$ concentration further increases. As a result, the average PCE increases from $18.25 \pm 0.50 \%$ for 0 wt $\%$ $\mathrm{Pb}(\mathrm{SCN})_{2}$ cells to $19.40 \pm 0.32 \%$ for the optimal $3 \mathrm{wt} \%$ devices. Higher concentrations of $\mathrm{Pb}(\mathrm{SCN})_{2}$ (above $4 \mathrm{wt} \%$ ) leads to reduced PCE of PVSCs, primarily due to the reduced $V_{\mathrm{OC}}$ although there is a slight decrease in $J_{\mathrm{SC}}$ for the highest $\mathrm{Pb}(\mathrm{SCN})_{2}$ concentration devices. On the other hand, it is worth mentioning that large perovskite grain sizes also reduce the observed $J$-V hysteresis. ${ }^{[4]}$ The FF and PCE differences measured under reverse and forward voltage scans, ${ }^{[54]}$ are shown in Fig. 4(e) and (f), respectively. The FF and PCE differences (values measured under reverse voltage scan - values measured under forward voltage scan) decrease as the $\mathrm{Pb}(\mathrm{SCN})_{2}$ concentration increases, which can be ascribed to the increased perovskite grain size that leads to reduced density of grain boundaries and $\mathrm{PbI}_{2}$ passivation of grain boundaries. Representative $J-V$ curves of $\mathrm{MA}_{0.7} \mathrm{FA}_{0.3} \mathrm{PbI}_{3}$ PVSCs with various amounts of $\mathrm{Pb}(\mathrm{SCN})_{2}$ additive are shown in Fig. S6. 

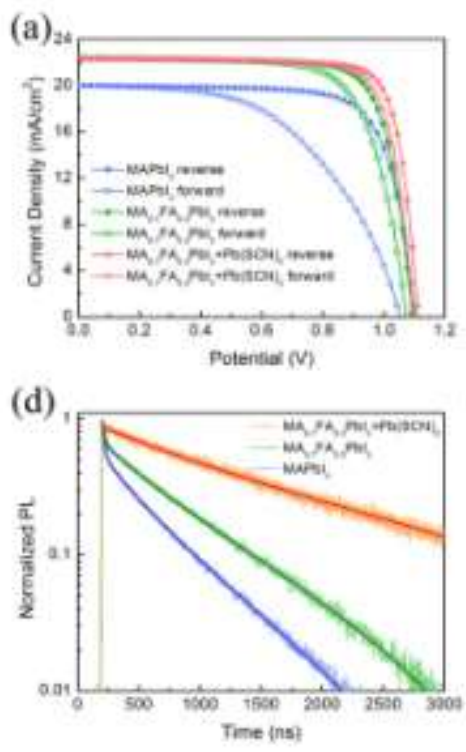

(b)

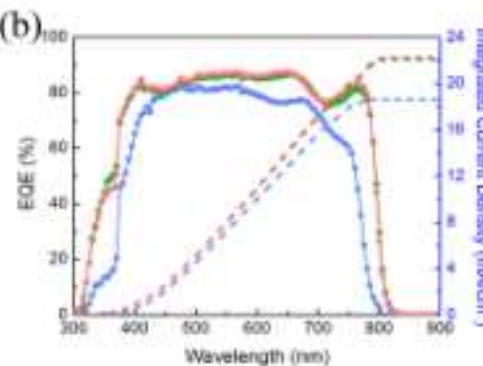

(e)

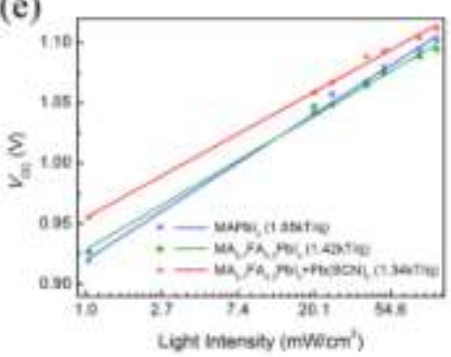

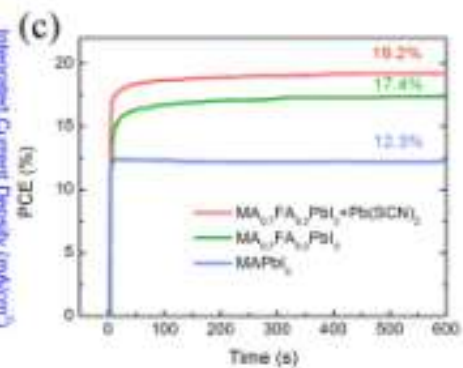

(f)

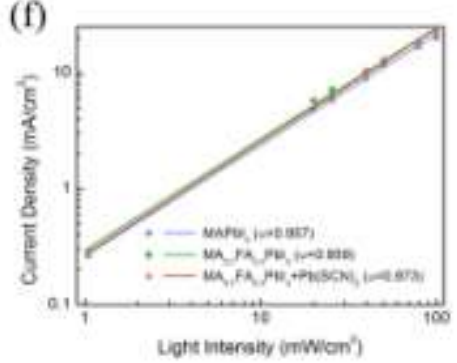

Fig. 5. (a) $J-V$ curves, (b) EQE spectra and (c) stabilized PCEs of PVSCs based on $\mathrm{MAPbI}_{3}, \mathrm{MA}_{0.7} \mathrm{FA}_{0.3} \mathrm{PbI}_{3}$ and $\mathrm{MA}_{0.7} \mathrm{FA}_{0.3} \mathrm{PbI}_{3}+3 \mathrm{wt} \% \mathrm{~Pb}(\mathrm{SCN})_{2}$, respectively. (d) PL decays of three perovskite films. (e) $V_{\mathrm{OC}}$ and (f) $J_{\mathrm{SC}}$ versus light intensity of PVSCs with $\mathrm{MAPbI}_{3}, \mathrm{MA}_{0.7} \mathrm{FA}_{0.3} \mathrm{PbI}_{3}$ and $\mathrm{MA}_{0.7} \mathrm{FA}_{0.3} \mathrm{PbI}_{3}+3 \mathrm{wt} \% \mathrm{~Pb}(\mathrm{SCN})_{2}$.

Fig. 5 shows the comparison of the photovoltaic performance of PVSCs with absorbers of pure $\mathrm{MAPbI}_{3}, \mathrm{MA}_{0.7} \mathrm{FA}_{0.3} \mathrm{PbI}_{3}$ and $\mathrm{MA}_{0.7} \mathrm{FA}_{0.3} \mathrm{PbI}_{3}+3$ wt $\% \mathrm{~Pb}(\mathrm{SCN})_{2}$ additive. Their representative $J$ - $V$ curves under reverse and forward bias scans with a scan rate of $1 \mathrm{~V} / \mathrm{s}$ are shown in Fig. 5 (a). The device with pure $\mathrm{MAPbI}_{3}$ has a PCE of $16.49(11.19) \%$ with a $V_{\mathrm{OC}}$ of $1.102(1.054) \mathrm{V}$, a $J_{\mathrm{SC}}$ of $19.99(20.00) \mathrm{mA} / \mathrm{cm}^{2}$ and a FF of 74.85 (53.07) \% measured under reverse (forward) voltage scan. The PCE of the PVSC with $\mathrm{MA}_{0.7} \mathrm{FA}_{0.3} \mathrm{PbI}_{3}$ is increased to 18.87 (17.27) \%, with a $V_{\mathrm{OC}}$ of 1.094 (1.075) $\mathrm{V}$, a $J_{\mathrm{SC}}$ of $22.37(22.37) \mathrm{mA} / \mathrm{cm}^{2}$ and a $\mathrm{FF}$ of $77.11(71.81) \%$ measured under reverse (forward) scan. It is clear that the $J_{\mathrm{SC}}$ significantly increases due to the reduction in the $\mathrm{Eg}$ via $\mathrm{FA}$ substitution. With the $\mathrm{Pb}(\mathrm{SCN})_{2}$ added into the mixed precursors, the $\mathrm{MA}_{0.7} \mathrm{FA}_{0.3} \mathrm{PbI}_{3}$ PVSCs shows a $V_{\mathrm{OC}}$ of $1.112(1.098) \mathrm{V}$, a $J_{\mathrm{SC}}$ of 22.34 (22.34) $\mathrm{mA} / \mathrm{cm}^{2}$ and a FF of $80.71(78.87) \%$, generating a PCE of $20.03(19.35) \%$ 
under reverse (forward) scan direction. The integrated $J_{\mathrm{SC}}$ 's from the EQE spectra are 18.64, 22.08 and $22.24 \mathrm{~mA} / \mathrm{cm}^{2}$ for PVSCs with pure $\mathrm{MAPbI}_{3}, \mathrm{MA}_{0.7} \mathrm{FA}_{0.3} \mathrm{PbI}_{3}$ and $\mathrm{MA}_{0.7} \mathrm{FA}_{0.3} \mathrm{PbI}_{3}+3 \mathrm{wt} \% \mathrm{~Pb}(\mathrm{SCN})_{2}$, respectively, which are in good agreement with the $J_{\mathrm{SC}}$ 's obtained from their $J-V$ curves shown in Fig. 5(b). The PVSCs show increased stabilized power output with these alterations in the perovskite layer (Fig. 5(c)). The stabilized PCEs are $12.3 \%, 17.4 \%$ and $19.2 \%$ for the PVSCs with pure $\mathrm{MAPbI}_{3}$, $\mathrm{MA}_{0.7} \mathrm{FA}_{0.3} \mathrm{PbI}_{3}$ and $\mathrm{MA}_{0.7} \mathrm{FA}_{0.3} \mathrm{PbI}_{3}+3 \mathrm{wt} \% \mathrm{~Pb}(\mathrm{SCN})_{2}$, respectively. The enhancement in $V_{\mathrm{OC}}$ and FF can be ascribed to the enlarged grain size (Fig. S4) and prolonged carrier lifetime, as obtained from TRPL results in Fig. 5 (d). The average carrier lifetimes obtained from the fit are $470 \mathrm{~ns}, 635 \mathrm{~ns}$ and $1071 \mathrm{~ns}$ for pure $\mathrm{MAPbI}_{3}$, $\mathrm{MA}_{0.7} \mathrm{FA}_{0.3} \mathrm{PbI}_{3}$, and $\mathrm{MA}_{0.7} \mathrm{FA}_{0.3} \mathrm{PbI}_{3}+3 \mathrm{wt} \% \mathrm{~Pb}(\mathrm{SCN})_{2}$, respectively. The dependence of $V_{\mathrm{OC}}$ and $J_{\mathrm{SC}}$ on light intensity ranging from 1 to $100 \mathrm{~mW} / \mathrm{cm}^{2}$ is shown in Fig. 5(e) and (f). The $V_{\mathrm{OC}}$ has a linear relationship with natural logarithmic light intensity, giving the fitted slopes of $1.55,1.42$ and $1.34 \mathrm{kT} / \mathrm{q}$ for PVSCs of pure $\mathrm{MAPbI}_{3}$, $\mathrm{MA}_{0.7} \mathrm{FA}_{0.3} \mathrm{PbI}_{3}$ and $\mathrm{MA}_{0.7} \mathrm{FA}_{0.3} \mathrm{PbI}_{3}+3$ wt $\% \mathrm{~Pb}(\mathrm{SCN})_{2}$, respectively. The results reveal the presence of Shockley-Read-Hall recombination in these PVSCs. However, the PVSC with $\quad \mathrm{MA}_{0.7} \mathrm{FA}_{0.3} \mathrm{PbI}_{3}+3 \quad$ wt $\% \quad \mathrm{~Pb}(\mathrm{SCN})_{2}$ shows lower trap-assisted recombination (lower slope) than the PVSC with $\mathrm{MA}_{0.7} \mathrm{FA}_{0.3} \mathrm{PbI}_{3}$, which is still lower than for the PVSC with pure $\mathrm{MAPbI}_{3}$. The power law dependence of $J_{\mathrm{SC}}$ on the light intensity shows a linear relation in a double logarithmic scale. The fitted slopes $(\alpha)$ of these three PVSCs are $0.957,0.959$ and 0.973 for PVSCs of pure $\mathrm{MAPbI}_{3}$, $\mathrm{MA}_{0.7} \mathrm{FA}_{0.3} \mathrm{PbI}_{3}$ and $\mathrm{MA}_{0.7} \mathrm{FA}_{0.3} \mathrm{PbI}_{3}+3$ wt $\% \mathrm{~Pb}(\mathrm{SCN})_{2}$, respectively. It has been 
reported that a solar cell with no space charge limited photocurrents will give a slope of $1 .{ }^{[55]}$ The PVSC with $\mathrm{MA}_{0.7} \mathrm{FA}_{0.3} \mathrm{PbI}_{3}+3$ wt $\% \mathrm{~Pb}(\mathrm{SCN})_{2}$ has more balanced charge carrier transportation than the pure $\mathrm{MAPbI}_{3}$ and $\mathrm{MA}_{0.7} \mathrm{FA}_{0.3} \mathrm{PbI}_{3} \mathrm{PVSCs}$ due to the improved perovskite film quality. Fig. S7 shows cross-sectional SEM images of devices with three different absorbers, $\mathrm{MAPbI}_{3}, \quad \mathrm{MA}_{0.7} \mathrm{FA}_{0.3} \mathrm{PbI}_{3}$, and $\mathrm{MA}_{0.7} \mathrm{FA}_{0.3} \mathrm{PbI}_{3}+3 \mathrm{wt} \% \mathrm{~Pb}(\mathrm{SCN})_{2}$. The absorber layers have a very similar thickness of about $500 \mathrm{~nm}$. The $\mathrm{MAPbI}_{3}$ and $\mathrm{MA}_{0.7} \mathrm{FA}_{0.3} \mathrm{PbI}_{3}$ thin films have small grains with sizes smaller than the film thickness. Therefore, the absorbers contain horizontal grain boundaries, presenting a significant risk for recombination of photogenerated electrons and holes when they travel through the absorber layer. However, the $\mathrm{MA}_{0.7} \mathrm{FA}_{0.3} \mathrm{PbI}_{3}+3 \mathrm{wt} \% \mathrm{~Pb}(\mathrm{SCN})_{2}$ film shows much larger grains with sizes larger than the film thickness. The absence of horizontal grain boundaries should result in a much lower rate of carrier recombination, leading to improved device performances.
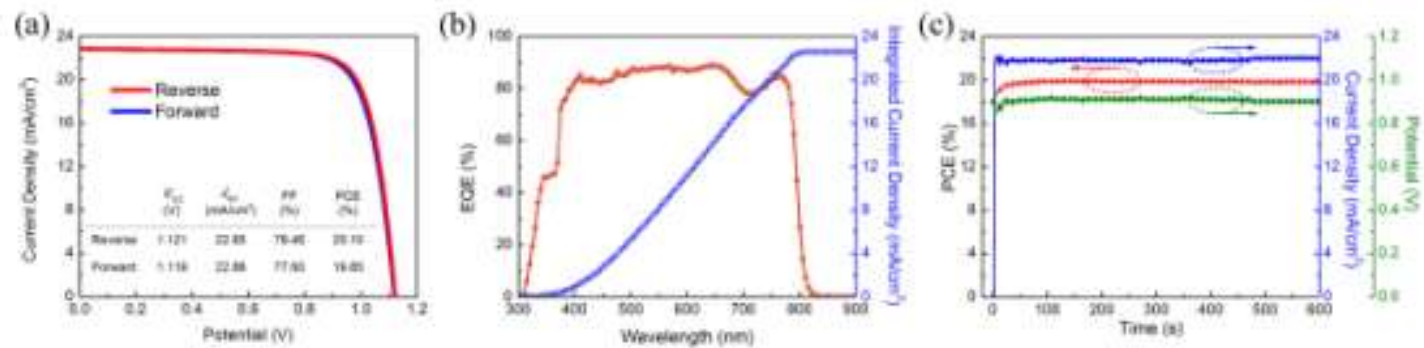

Fig. 6. (a) The $J-V$ curves of the best-performing PVSC measured under reverse and forward scans, (b) the corresponding EQE spectrum and integrated photocurrent density. (c) PCE, photocurrent density and voltage measured using maximum power point tracking method.

Our best-performing PVSC with $\mathrm{MA}_{0.7} \mathrm{FA}_{0.3} \mathrm{PbI}_{3}+3 \mathrm{wt} \% \mathrm{~Pb}(\mathrm{SCN})_{2}$ shows a PCE of $20.10(19.85) \%$ with a $V_{\mathrm{OC}}$ of $1.121(1.119) \mathrm{V}$, a $J_{\mathrm{SC}}$ of $22.85(22.86) \mathrm{mA} / \mathrm{cm}^{2}$ and a FF of 78.46 (77.60) \% measured under reverse (forward) voltage scan, showing a 
very small degree of $J$ - $V$ hysteresis (Fig. 6(a)). The corresponding EQE spectrum and integrated current density under a standard AM 1.5G spectrum are shown in Fig. 6(b). The EQE-integrated $J_{\mathrm{SC}}$ is $22.60 \mathrm{~mA} / \mathrm{cm}^{2}$, consistent with the $J_{\mathrm{SC}}$ obtained from the $J$ - $V$ curve. Fig. $6($ c) shows the maximum power output of $\sim 19.8 \%$ measured using the maximum power point tracking method. The power output of this PVSC is very stable under one sun illumination for 600 seconds without any isolation from the ambient environment, during which time no significant degradation was observed. The current density $\left(\sim 21.7 \mathrm{~mA} / \mathrm{cm}^{2}\right)$ hardly changed while the voltage increased slightly in the first several seconds under illumination then achieved a stable value of $0.91 \mathrm{~V}$. The stable power output is consistent with the value obtained from $J$ - $V$ curve.
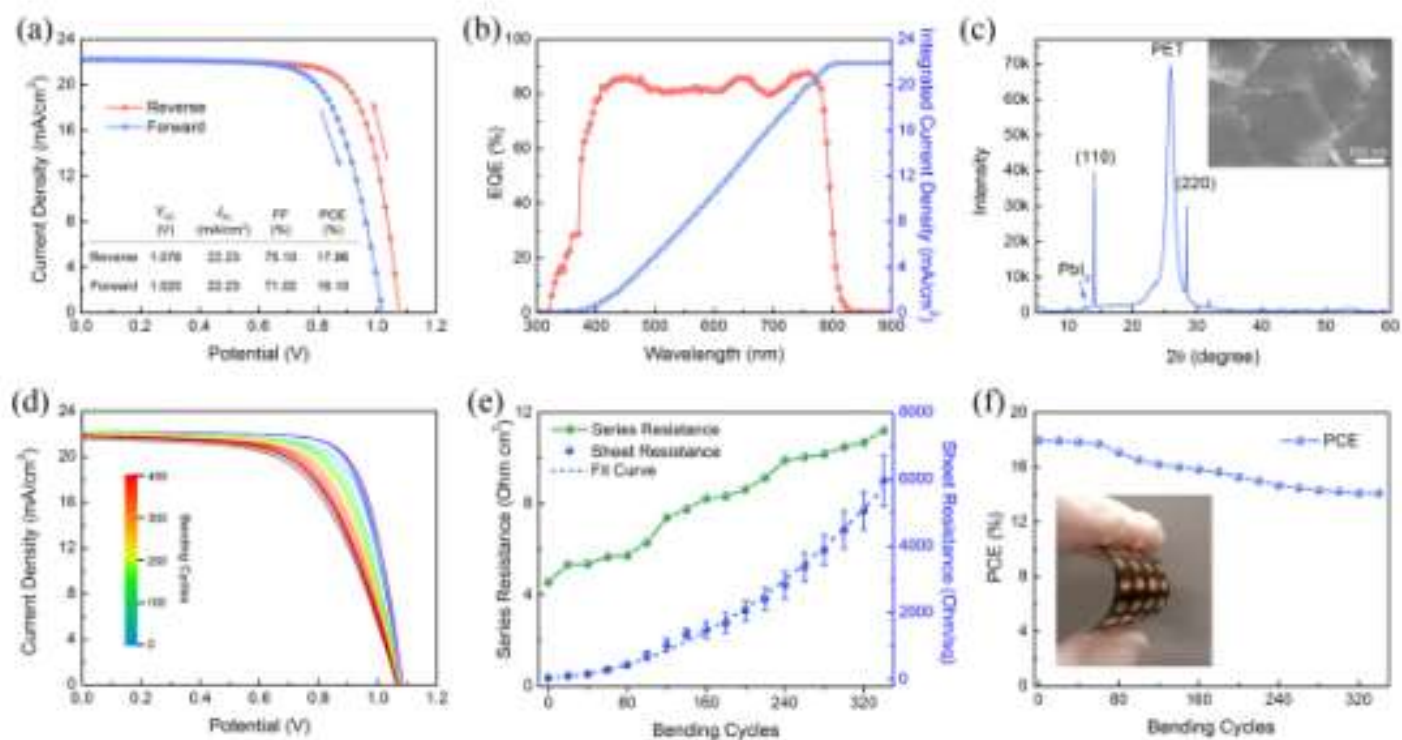

Fig. 7. (a) The $J-V$ curves of the best-performing flexible PVSC measured under reverse and forward scans with a scan rate of $1 \mathrm{~V} / \mathrm{s}$, (b) the corresponding EQE spectrum and integrated photocurrent density of $21.90 \mathrm{~mA} / \mathrm{cm}^{2}$. (c) XRD pattern and top-view SEM image (inset) of perovskite films on ITO/PET substrate. (d) The $J$ - $V$ curves of the flexible PVSC with various bending cycles under reverse voltage scan. (e) The series resistance of the flexible PVSC calculated from the $J-V$ curves and the sheet resistance of the ITO/PET substrate with various bending cycles. (f) PCE of the flexible PVSC with various bending cycles. 
The low-temperature fabrication process is particularly beneficial for making flexible PVSCs. We have fabricated flexible PVSCs on indium-doped $\mathrm{SnO}_{2}$ (ITO)/polyethylene terephthalate (PET) substrates. The compositional and morphological egenieering conditions optimied for PVSCs fabricated on glass substrates are suitable for flexible PVSCs on PET substrates. The $J$ - $V$ curves under reverse and forward scans of the best-performing flexible PVSC are shown in Fig. 7(a), exhibiting a PCE of $17.96(16.10) \%$ with a $V_{\mathrm{OC}}$ of $1.076(1.020) \mathrm{V}$, a $J_{\mathrm{SC}}$ of $22.23(22.23) \mathrm{mA} / \mathrm{cm}^{2}$ and a FF of $75.10(71.02) \%$ when measured under reverse (forward) voltage scan with a sweep rate of $1 \mathrm{~V} / \mathrm{s}$. The degrees of hysteresis of the flexible PVSCs are higher than the PVSCs fabricated on rigid FTO glass substrates. This is likely due to the relatively higher sheet resistance of the ITO/PET substrate $(\sim 45 \Omega / \square)$ compared to that of FTO glass substate $(\sim 15 \Omega / \square)$. The integrated current density from the EQE spectrum of this flexible PVSC is $21.90 \mathrm{~mA} / \mathrm{cm}^{2}$ as shown in Fig. 7(b), in good agreement with the $J_{\mathrm{SC}}$ value obtained from $J-V$ curve. The XRD pattern and SEM image of the $\mathrm{MA}_{0.7} \mathrm{FA}_{0.3} \mathrm{PbI}_{3}+3$ wt $\% \mathrm{~Pb}(\mathrm{SCN})_{2}$ perovskite film deposited on ITO/PET substrate are shown in Fig. 7(c), revealing the successful formation of high quality perovskite film. We have also measured the effect of bending fatigue cycles on device performanceon as shown in Fig. 7(d), (e) and (f). The $J-V$ curve of flexible PVSC under reverse scan shows that FF decreases significantly with the increase number of bending, which can be ascribed to the dramatically increased sheet resistance of the flexible ITO/PET substrate as shown in Fig. 7(e), which leads to the increased series resistance of the PVSC. This is 
consistent with Figure S8, showing no obvious change on the film morphology after 340 times bending. After 340 bending with a minimum radius of curvature of $5 \mathrm{~mm}$, the PCE is maintained at $14.30 \%$, approximately $80 \%$ of its initial PCE of $17.96 \%$, indicating a good flexibility endurance of our flexible PVSCs. The image of our flexible PVSC is shown as the inset of Fig. 7(f). Therefore, higher performance flexible PVSCs are expected if flexible substrates with higher conductivity and better bending endurance become available. ${ }^{[56]}$

\section{Conclusion}

We have employed compositional and morphological engineering of mixed $\mathrm{MA}_{1-\mathrm{x}} \mathrm{FA}_{\mathrm{x}} \mathrm{PbI}_{3}$ perovskite absorber layers to improve the performance of planar PVSCs. The alloying of FA and MA extends the absorption edge of the perovskite absorbers to longer wavelengths, leading to enhanced $J_{\mathrm{SC}}$. The introduction of a small amount of $\mathrm{Pb}(\mathrm{SCN})_{2}$ into the perovskite precursors enlarges the grain size and prolongs the charge carrier lifetimes in the perovskite films, leading to significant improvement in $V_{\mathrm{OC}}$ 's and FFs in the resultant devices. With optimal compositional and morphological engineering, the average PCE improves from $15.74 \pm 0.74 \%$ for pure $\mathrm{MAPbI}_{3} \mathrm{PVSC}$ to $19.40 \pm 0.32 \%$ for $\mathrm{MA}_{0.7} \mathrm{FA}_{0.3} \mathrm{PbI}_{3}$ PVSCs with $3 \% \mathrm{~Pb}(\mathrm{SCN})_{2}$ additive. Our best-performing planar $\mathrm{MA}_{0.7} \mathrm{FA}_{0.3} \mathrm{PbI}_{3}$ PVSC (with $3 \% \mathrm{~Pb}(\mathrm{SCN})_{2}$ additive) has achieved a PCE of 20.10 (19.85) \% when measured under reverse (forward) voltage scan. The flexible PVSC shows a very high efficiency of $17.96 \%$ under reverse scan. Our results suggest that incorporating $\mathrm{Pb}(\mathrm{SCN})_{2}$ additive in the 
precursors is an effective approach for fabricating highly efficient planar mixed cation PVSCs with reduced hysteresis and high reproducibility.

\section{Acknowledgements}

This work is financially supported by the U.S. Department of Energy (DOE) SunShot Initiative under the Next Generation Photovoltaics 3 program (DE-FOA-0000990), National Science Foundation under contract no. CHE-1230246 and DMR-1534686, and the Ohio Research Scholar Program. N. Shrestha thanks the U.S. Air Force Research Laboratory for support under contract \# FA9453-11-C-0253. This work also received financial support from National Basic Research Program of China (2011CB933300), National Science Fund for Distinguished Young Scholars (50125309), National Natural Science Foundation of China (Grants 51272184 and 91433203). J. Chen thanks the partially financial support from National Key R\&D Program of China 2016YFB0401600, National Natural Science Foundation Project (61674029), and Natural Science Foundation Project of Jiangsu Province (BK20151417).

\section{Appendix A. Supporting Information Available}

Supplementary data associated with this article can be found in the online version at http://dx.doi.org/.

\section{References}

[1] A. Kojima, K. Teshima, Y. Shirai, T. Miyasaka, J. Am. Chem. Soc. 131 (2009) 6050-6051.

[2] M. M. Lee, J. Teuscher, T. Miyasaka, T. N. Murakami, H. J. Snaith, Science 338 (2012) 643-647.

[3] M. Liu, M. B. Johnston, H. J. Snaith, nature 501 (2013) 395-398. 
[4] D. P. McMeekin, G. Sadoughi, W. Rehman, G. E. Eperon, M. Saliba, M. T. Hörantner, A. Haghighirad, N. Sakai, L. Korte, B. Rech, M. B. Johnston, L. M. Herz, H. J. Snaith, Science 351 (2016) 151-155.

[5] N. J. Jeon, J. H. Noh, W. S. Yang, Y. C. Kim, S. Ryu, J. Seo, S. I. Seok, Nature 517 (2015) 476-480.

[6] W. S. Yang, J. H. Noh, N. J. Jeon, Y. C. Kim, S. Ryu, J. Seo, S. I. Seok, Science 348 (2015) 1234-1237.

[7] M. Saliba, T. Matsui, K. Domanski, J.-Y. Seo, A. Ummadisingu, S. M. Zakeeruddin, J.-P. Correa-Baena, W. R. Tress, A. Abate, A. Hagfeldt, M. Grätzel, Science 354 (2016) 206-209.

[8] D. Bi, W. Tress, M. I. Dar, P. Gao, J. Luo, C. Renevier, K. Schenk, A. Abate, F. Giordano, J.-P. C. Baena, Sci. Adv. 2 (2016) e1501170.

[9] A. Mei, X. Li, L. Liu, Z. Ku, T. Liu, Y. Rong, M. Xu, M. Hu, J. Chen, Y. Yang, Science 345 (2014) 295-298.

[10] W. Liao, D. Zhao, Y. Yu, C. R. Grice, C. Wang, A. J. Cimaroli, P. Schulz, W. Meng, K. Zhu, R.-G. Xiong, Y. Yan, Adv. Mater. 28 (2016) 9333-9340.

[11] W. Liao, D. Zhao, Y. Yu, N. Shrestha, K. Ghimire, C. R. Grice, C. Wang, Y. Xiao, A. J. Cimaroli, R. J. Ellingson, N. J. Podraza, K. Zhu, R.-G. Xiong, Y. Yan, J. Am. Chem. Soc. 138 (2016) 12360-12363.

[12] Z. Yu, B. Chen, P. Liu, C. Wang, C. Bu, N. Cheng, S. Bai, Y. Yan, X. Zhao, Adv. Funct. Mater. 26 (2016) 4866-4873.

[13] Z. Song, A. Abate, S. C. Watthage, G. K. Liyanage, A. B. Phillips, U. Steiner, M. Graetzel, M. J. Heben, Adv. Energy Mater. 6 (2016) 1600846.

[14] B. Chen, Y. Bai, Z. Yu, T. Li, X. Zheng, Q. Dong, L. Shen, M. Boccard, A. Gruverman, Z. Holman, J. Huang, Adv. Energy Mater. 6 (2016) 1601128.

[15] W. Shockley, H. J. Queisser, J. Appl. Phys. 32 (1961) 510-519.

[16] M. A. Green, Prog. Photovolt: Res. Appl. 20 (2012) 472-476.

[17] S. Pang, H. Hu, J. Zhang, S. Lv, Y. Yu, F. Wei, T. Qin, H. Xu, Z. Liu, G. Cui, Chem. Mater. 26 (2014) 1485-1491.

[18] G. E. Eperon, S. D. Stranks, C. Menelaou, M. B. Johnston, L. M. Herz, H. J. Snaith, Energy Environ. Sci. 7 (2014) 982-988.

[19] F. Wang, H. Yu, H. Xu, N. Zhao, Adv. Funct. Mater. 25 (2015) 1120-1126.

[20] S. Aharon, A. Dymshits, A. Rotem, L. Etgar, J. Mater. Chem. A 3 (2015) 9171-9178.

[21] M. Saliba, T. Matsui, J.-Y. Seo, K. Domanski, J.-P. Correa-Baena, M. K. Nazeeruddin, S. M. Zakeeruddin, W. Tress, A. Abate, A. Hagfeldt, M. Gratzel, Energy Environ. Sci. 9 (2016) 1989-1997.

[22] Z. Song, S. C. Watthage, A. B. Phillips, B. L. Tompkins, R. J. Ellingson, M. J. Heben, Chem. Mater. 27 (2015) 4612-4619.

[23] Z. Yang, C.-C. Chueh, P.-W. Liang, M. Crump, F. Lin, Z. Zhu, A. K. Y. Jen, Nano Energy 22 (2016) 328-337.

[24] Y. Yu, C. Wang, C. R. Grice, N. Shrestha, J. Chen, D. Zhao, W. Liao, A. J. Cimaroli, P. J. Roland, R. J. Ellingson, Y. Yan, ChemSusChem 9 (2016) 3288-3297.

[25] Z. Li, M. Yang, J.-S. Park, S.-H. Wei, J. J. Berry, K. Zhu, Chem. Mat. 28 (2016) 284-292.

[26] Y. Deng, Q. Dong, C. Bi, Y. Yuan, J. Huang, Adv. Energy Mater. 6 (2016) 1600372.

[27] D. Zhao, W. Ke, C. R. Grice, A. J. Cimaroli, X. Tan, M. Yang, R. W. Collins, H. Zhang, K. Zhu, Y. Yan, Nano Energy 19 (2016) 88-97. 
[28] D. Zhao, M. Sexton, H. Y. Park, G. Baure, J. C. Nino, F. So, Adv. Energy Mater. 5 (2015) 1401855.

[29] W. Li, J. Fan, Y. Mai, L. Wang, Adv. Energy Mater. 7 (2016) 1601433.

[30] W. Nie, H. Tsai, R. Asadpour, J.-C. Blancon, A. J. Neukirch, G. Gupta, J. J. Crochet, M. Chhowalla, S. Tretiak, M. A. Alam, H.-L. Wang, A. D. Mohite, Science 347 (2015) 522-525.

[31] Z. Xiao, Q. Dong, C. Bi, Y. Shao, Y. Yuan, J. Huang, Adv. Mater. 26 (2014) 6503-6509.

[32] X. Meng, Y. Bai, S. Xiao, T. Zhang, C. Hu, Y. Yang, X. Zheng, S. Yang, Nano Energy 30 (2016) 341-346.

[33] Y. Shao, Z. Xiao, C. Bi, Y. Yuan, J. Huang, Nat. Commun. 5 (2014) 5784.

[34] Q. Chen, H. Zhou, T.-B. Song, S. Luo, Z. Hong, H.-S. Duan, L. Dou, Y. Liu, Y. Yang, Nano Lett. 14 (2014) 4158-4163.

[35] X. Liu, F. Lin, C.-C. Chueh, Q. Chen, T. Zhao, P.-W. Liang, Z. Zhu, Y. Sun, A. K. Y. Jen, Nano Energy 30 (2016) 417-425.

[36] S. Song, B. J. Moon, M. T. Hörantner, J. Lim, G. Kang, M. Park, J. Y. Kim, H. J. Snaith, T. Park, Nano Energy 28 (2016) 269-276.

[37] Z.-L. Tseng, C.-H. Chiang, S.-H. Chang, C.-G. Wu, Nano Energy 28 (2016) 311-318.

[38] X. Sun, C. Zhang, J. Chang, H. Yang, H. Xi, G. Lu, D. Chen, Z. Lin, X. Lu, J. Zhang, Y. Hao, Nano Energy 28 (2016) 417-425.

[39] R. Fan, Y. Huang, L. Wang, L. Li, G. Zheng, H. Zhou, Adv. Energy Mater. 6 (2016) 1600460.

[40] M. Li, Z.-K. Wang, Y.-G. Yang, Y. Hu, S.-L. Feng, J.-M. Wang, X.-Y. Gao, L.-S. Liao, Adv. Energy Mater. 6 (2016) 1601156.

[41] Z. Li, J. Tinkham, P. Schulz, M. Yang, D. H. Kim, J. Berry, A. Sellinger, K. Zhu, Adv. Energy Mater. 7 (2017) 1601451.

[42] W. Ke, D. Zhao, C. R. Grice, A. J. Cimaroli, J. Ge, H. Tao, H. Lei, G. Fang, Y. Yan, J. Mater. Chem. A 3 (2015) 17971-17976.

[43] D. Zhao, Y. Yu, C. Wang, W. Liao, N. Shrestha, C. R. Grice, A. J. Cimaroli, L. Guan, R. J. Ellingson, K. Zhu, X. Zhao, R.-G. Xiong, Y. Yan, Nat. Energy 2 (2017) 17018.

[44] W. Ke, C. Xiao, C. Wang, B. Saparov, H.-S. Duan, D. Zhao, Z. Xiao, P. Schulz, S. P. Harvey, W. Liao, W. Meng, Y. Yu, A. J. Cimaroli, C.-S. Jiang, K. Zhu, M. Al-Jassim, G. Fang, D. B. Mitzi, Y. Yan, Adv. Mater. 28 (2016) 5214-5221.

[45] C. Wang, D. Zhao, C. R. Grice, W. Liao, Y. Yu, A. Cimaroli, N. Shrestha, P. J. Roland, J. Chen, Z. Yu, P. Liu, N. Cheng, R. J. Ellingson, X. Zhao, Y. Yan, J. Mater. Chem. A 4 (2016) 12080-12087.

[46] N. Ahn, D.-Y. Son, I.-H. Jang, S. M. Kang, M. Choi, N.-G. Park, J. Am. Chem. Soc. 137 (2015) 8696-8699.

[47] J.-W. Lee, H.-S. Kim, N.-G. Park, Acc. Chem. Res. 49 (2016) 311-319.

[48] J.-W. Lee, D.-J. Seol, A.-N. Cho, N.-G. Park, Adv. Mater. 26 (2014) 4991-4998.

[49] J. Peng, T. Duong, X. Zhou, H. Shen, Y. Wu, H. K. Mulmudi, Y. Wan, D. Zhong, J. Li, T. Tsuzuki, K. J. Weber, K. R. Catchpole, T. P. White, Adv. Energy Mater. 7 (2017) 1601768.

[50] J.-W. Lee, D.-H. Kim, H.-S. Kim, S.-W. Seo, S. M. Cho, N.-G. Park, Adv. Energy Mater. 5 (2015) 1501310 .

[51] K. Wojciechowski, S. D. Stranks, A. Abate, G. Sadoughi, A. Sadhanala, N. Kopidakis, G. Rumbles, C.-Z. Li, R. H. Friend, A. K. Y. Jen, H. J. Snaith, ACS nano 8 (2014) 12701-12709.

[52] X. Liu, K.-W. Tsai, Z. Zhu, Y. Sun, C.-C. Chueh, A. K. Y. Jen, Adv. Mater. Interfaces 3 (2016) 1600122 . 
[53] B. Roose, J.-P. C. Baena, K. C. Gödel, M. Graetzel, A. Hagfeldt, U. Steiner, A. Abate, Nano Energy 30 (2016) 517-522.

[54] E. H. Anaraki, A. Kermanpur, L. Steier, K. Domanski, T. Matsui, W. Tress, M. Saliba, A. Abate, M. Gratzel, A. Hagfeldt, J.-P. Correa-Baena, Energy Environ. Sci. 9 (2016) 3128-3134.

[55] V. Mihailetchi, J. Wildeman, P. Blom, Phys. Rev. Lett. 94 (2005) 126602.

[56] J. Yoon, H. Sung, G. Lee, W. Cho, N. Ahn, H. S. Jung, M. Choi, Energy Environ. Sci. 10 (2016) 337-345.

Changlei Wang is a Ph.D. student in Wuhan University under the supervision of Prof. Xingzhong Zhao. Currently, he is working in Prof. Yanfa Yan's group as a visiting scholar at The University of Toledo. His research interest is perovskite solar cells and synthesis of nanomaterials.

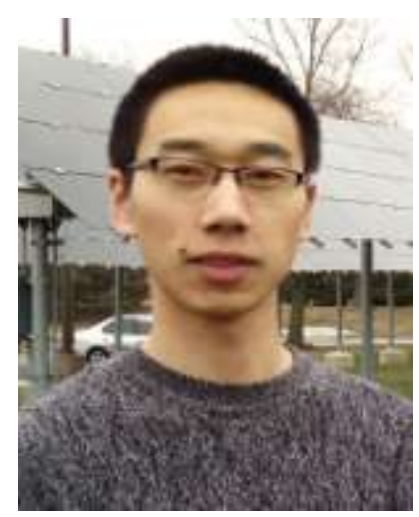

Dewei Zhao is a Research Assistant Professor in Wright Center for Photovoltaics Innovation and Commercialization and Department of Physics and Astronomy at The University of Toledo. He received his Ph.D. degree in electrical engineering from Nanyang Technological University, Singapore in 2011. He joined Prof Yanfa Yan's group in 2014. His recent research is focused on vacuum-processed and solution-processed perovskite solar cells, including material synthesis, device fabrication/characterization, as well as organic optoelectronics such as solar cells and light-emitting diodes.

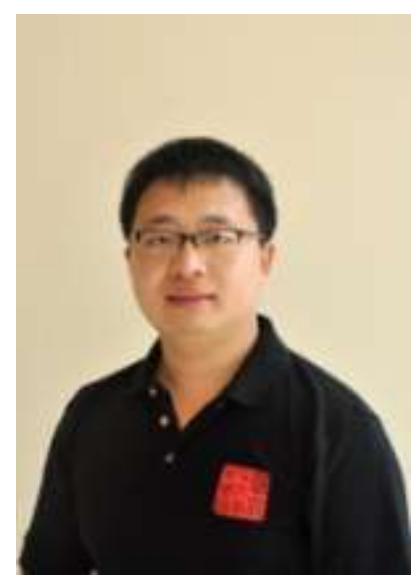


Yue Yu received her Bachelor of Science degree in Material Science and Engineering from the University of Science and Technology, Beijing in 2012. After graduating, she entered the University of Toledo for a Ph.D. degree in Physics with specialization in photovoltaics. She has broad research interests in thin film solar cells and photoelectrochemical water splitting. She is currently working on perovskite solar cell fabrications and characterizations.

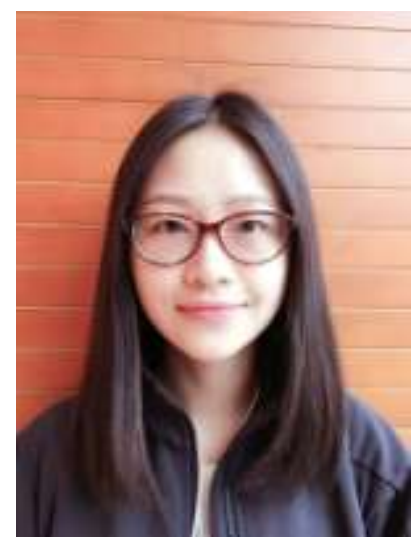

Niraj Shrestha is a Ph. D. student at University of Toledo. He received his MS degree from University of Memphis, Memphis, TN in 2013. His current research interests include study of semiconductor thin films based on their static and dynamic optical properties including techniques of ultrafast pump-probe spectroscopy, steady state photoluminescence spectroscopy and time resolved photoluminescence spectroscopy.

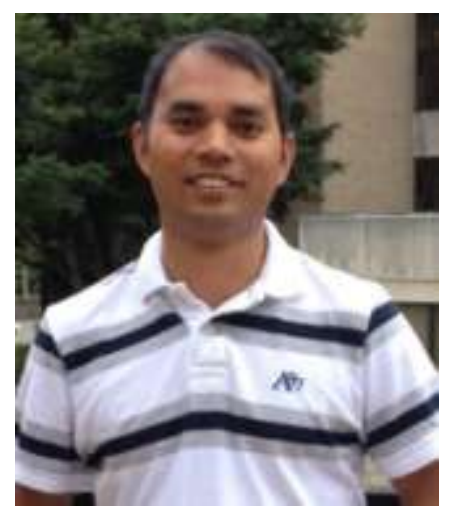

Corey R. Grice earned Bachelor of Science in Engineering degrees in Chemical Engineering and Materials Science \& Engineering from the University of Michigan in 2005. From 2005 until 2011 he worked in the private sector, primarily in fuel cell research and development. He entered graduate school at the University of Toledo in 2011 and completed a Professional Science Masters degree in Physics with specialization in Photovoltaics in 2013. He is currently pursuing a $\mathrm{PhD}$ in Physics under the guidance of Dr. Yanfa Yan, with research focusing on various novel and/or 
low cost thin film photovoltaic and photoelectrochemical materials and devices.

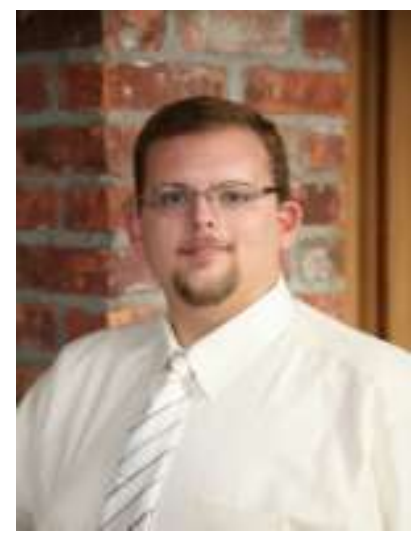

Weiqiang Liao received his Ph.D. degree in Materials Physics and Chemistry from Southeast University, China in 2017. He joined Prof Yanfa Yan's group in 2015 as a visiting scholar. His research interests include molecular ferroelectrics, organic-inorganic hybrid functional materials, and perovskite solar cells. $\mathrm{He}$ is currently working on ferroelectric photovoltaic solar cells.

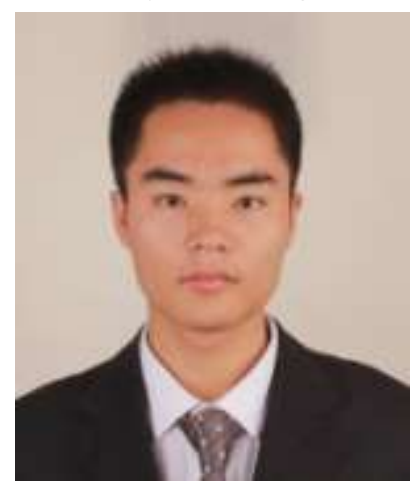

Alexander J Cimaroli received a B.S. in Applied Physics from Purdue University, West Lafayette, Indiana in 2010. He received his Ph.D. degree in the Physics department at the University of Toledo. His research focuses on thin film photovoltaic devices, device fabrication and characterization.

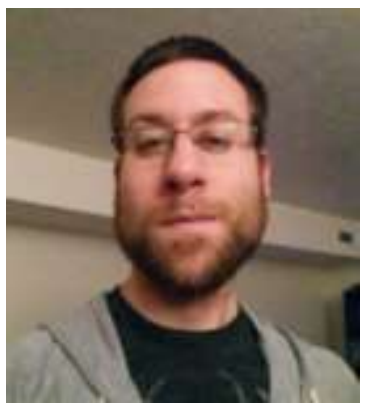

Jing Chen was born in China, in 1982. She received the B.S. degree in Chemistry from the Nanjing Normal University, China in 2001 and M.S. and the Ph.D. degrees in Physical Electronics from Southeast University, China in 2011. From 2011 to 2014, she was lecturer with Display and Research Centre of Southeast University. Since 2014, she has been an Associated Professor with School of Electronic Science and 
Engineering, Southeast University. She is the author of more than 50 articles, and hosts more than 10 patents. Her research interests include quantum dot synthesis and application of opt-electric devices, such as quantum dot sensitized solar cell, quantum dot light emitting diodes, sensors.

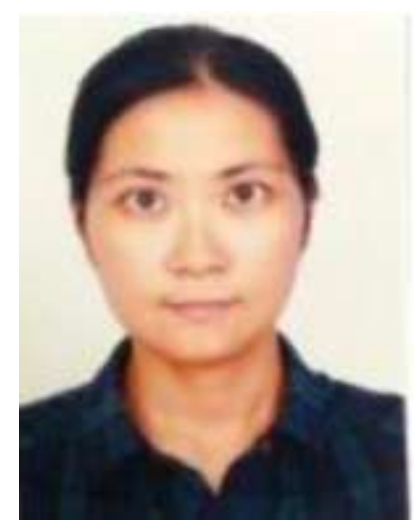

Randy Ellingson, Professor of Physics and faculty member of the University of Toledo's Wright Center for Photovoltaics Innovation and Commercialization, studies photovoltaic materials, devices, and systems. Methods include ultrafast and steady-state optical spectroscopies, synthesis and solution-processing of nanocrystalline and quantum-confined semiconductors, device modeling, and PV system modeling and energy production forecasting. He received his B.A. in Physics from Carleton College and his Ph.D. degree in Applied Physics from Cornell University. Following 14 years at the National Renewable Energy Laboratory in Colorado, he joined the University of Toledo in 2008 to focus on the application of advanced materials and characterization to commercially relevant solar energy technologies.

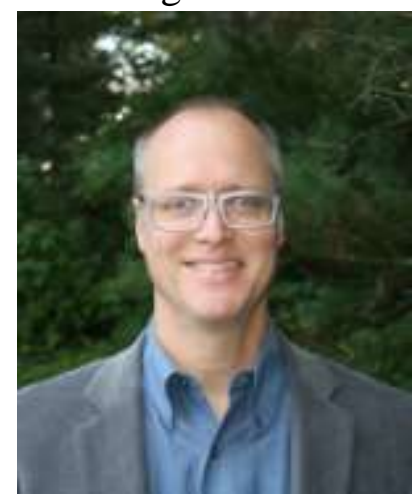

Xing-Zhong Zhao is a Cheung Kong Professor of Physics at Wuhan University, China. He received his Ph.D. from University of Science and Technology Beijing in 1989. From 1990 to 1995, he was an Assistant and Associate Professor at Huazhong University of Science and Technology. He then worked as an Adjunct Associate Professor and post doctorate research fellow at Pennsylvania State University 
(1995-1998). He visited MIT as a senior visiting scientist in 2006 for six months. His research interests include the dye-sensitized and perovskite solar cells, microfluidic-based enriching and isolation of circulating tumor cells and fetal nucleated red blood cells for biomedical analysis and diagnosis and related applications.

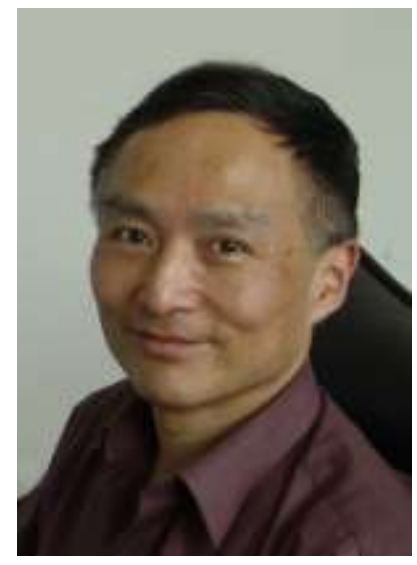

Yanfa Yan has been an Ohio Research Scholar Chair and Professor in the Department of Physics and Astronomy at The University of Toledo, since 2011. Previously, he was a Principal Scientist at the National Renewable Energy Laboratory. He earned his Ph. D. in Physics from Wuhan University in 1993. His expertise includes thin-film solar cell fabrication, defect physics of semiconductors, and nanoscale characterization of microstructures, interfaces, and defects in thin-film photovoltaic materials. He is a Fellow of the American Physical Society.

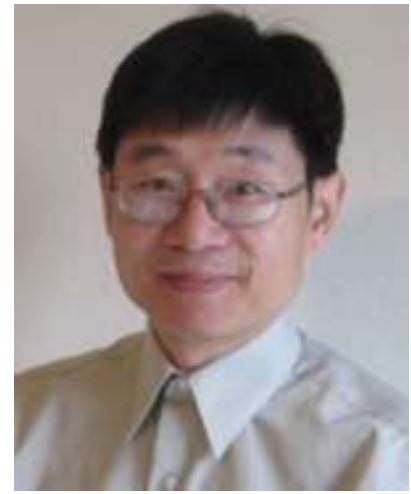




\section{Graphical Abstract}
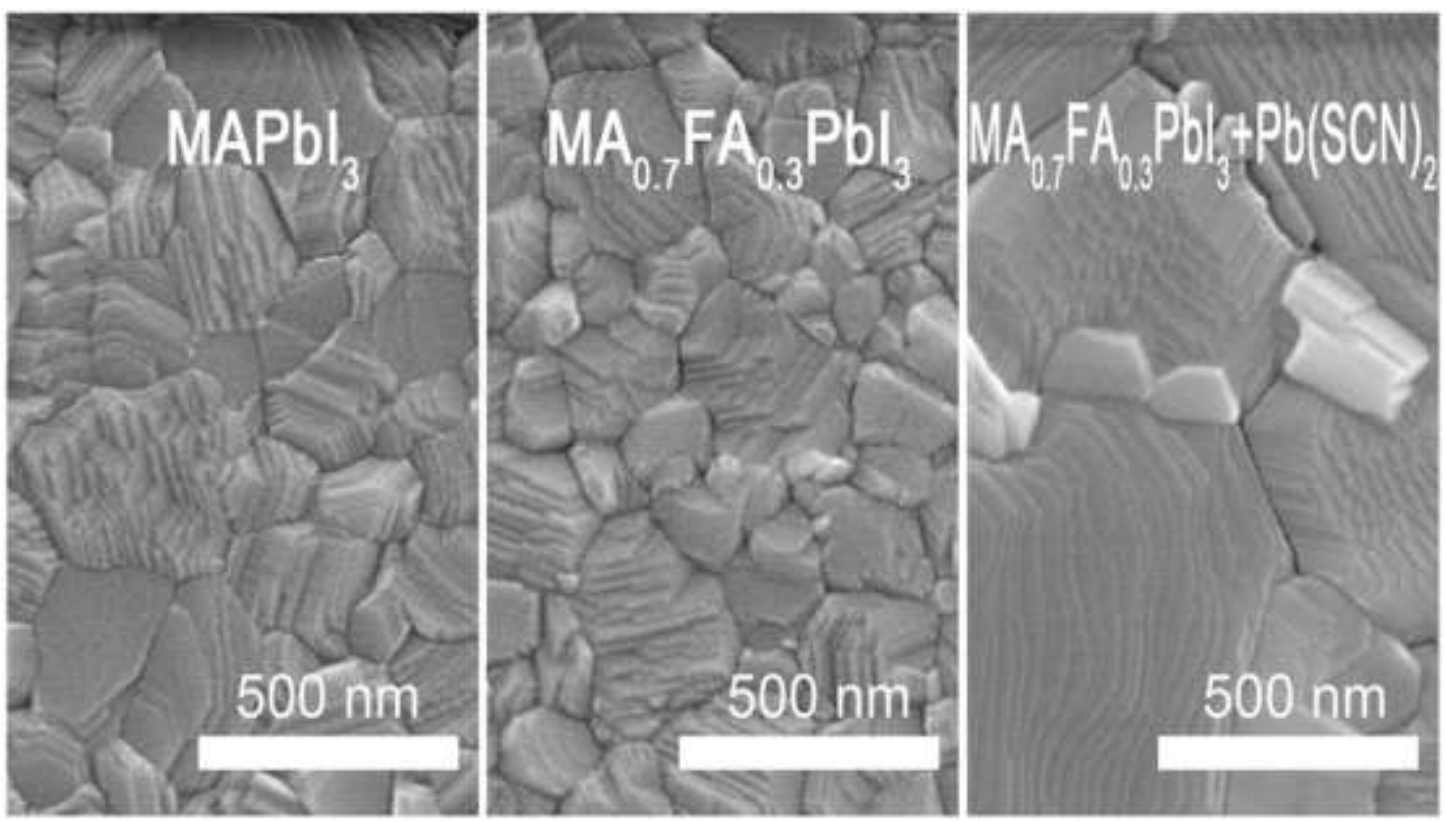

Mixing $\mathrm{MAPbI}_{3}$ precursor with $\mathrm{FAPbI}_{3}$ precursor with the presence of $\mathrm{Pb}(\mathrm{SCN})_{2}$ additive significantly improves crystal quality of mixed cation lead halide perovskite thin films and, therefore, the performances of the resulting perovskite solar cells. The low temperature $\left(100{ }^{\circ} \mathrm{C}\right)$ fabrication process enables us to achieve flexible perovskite solar cells efficiencies up to $17.96 \%$. 